Supplement of The Cryosphere, 13, 2511-2535, 2019

https://doi.org/10.5194/tc-13-2511-2019-supplement

(c) Author(s) 2019. This work is distributed under

the Creative Commons Attribution 4.0 License.

(c) (1)

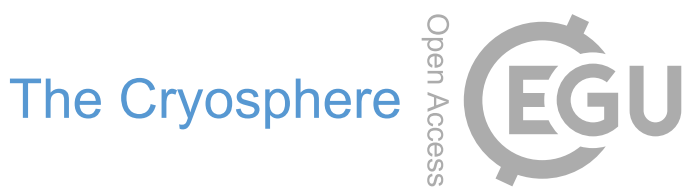

Supplement of

\title{
Heterogeneous spatial and temporal pattern of surface elevation change and mass balance of the Patagonian ice fields between 2000 and 2016
}

Wael Abdel Jaber et al.

Correspondence to: Wael Abdel Jaber (wael.abdeljaber@dlr.de)

The copyright of individual parts of the supplement might differ from the CC BY 4.0 License. 


\section{Contents}

\section{S1 TanDEM-X data}

The processed Raw DEMs are reported along with some relevant parameters in Tables S1 and S2 for NPI and SPI, respectively. The footprint of each scene (identified with an unique index within each icefield) is shown in Fig. S1.

\section{S2 SRTM data}

The datatakes contributing to the SRTM DEM on the Patagonian icefields are reported in Table S3. The elevation difference of two versions of SRTM (SRTMGL1 and NASADEM) and their differences versus the TanDEM-X global DEM used as reference are shown in Fig. S2. Statistics on stable terrain of the two TDM-SRTM DEM differences are reported in Table S4.

\section{S3 DEM coregistration and SECR derivation}

The absolute calibration of the single DEMs with respect to a reference DEM is performed on selected calibration regions (CRs), some of their features are summarized in Table S5. The procedure for artefact masking is summarized here.

\section{S4 Seasonal correction}

The average daily SECR measured on the summer 2011/2012 (for two subsets of glaciers) used to compensate for the missing summer days in the main SECR are plotted versus altitude in Fig. S3. The final correction layers are shown in Fig. S4. Follows a note on the surface mass balance elevation gradient for seasonal correction of the SECR on certain glaciers.

\section{S5 Radar backscatter of TanDEM-X and SRTM}

The mosaics of backscatter for the TanDEM-X coverages are shown in Fig. S5. The backscatter mean and standard deviation of the SRTM sub-swaths are shown in Fig. S6. Follows the procedure for the estimation of the height offsets due to radar signal penetration.

\section{S6 Uncertainty of SECR and mass balance}

The random error rasters for the SECR maps of the two epochs (2000-2012 and 2012-2016) are shown in Fig. S8. Two off-ice semivariograms of the SECR maps (TDM-SRTM and TDM-TDM) are plotted in Fig. S9 and the parameters of the exponential model fit are reported in Table S7. The average values of the systematic error components are reported for all produced SECR maps in Table S8.

\section{S7 Results}

A map displaying the obtained average SECR per glacier basin for the two epochs and the average elevation per basin is shown in Fig. S10. The hypsometric curve of the icefield highlighting the distribution of unsurveyed area is given in Fig. S11 and S12 for NPI and SPI, respectively. Hypsometric plots of surface elevation change rate (SECR), volume change rate (VCR) and mass change rate (MCR) for more glaciers than in the main paper are reported in Fig. S13 and S14 for NPI and SPI, respectively. The geodetic mass balance of smaller SPI glaciers is reported in Table S9. The frontal retreat distances and subaqueous volume change estimates for SPI glaciers during the period 2000-2011/2012 are given in Table S10.

\section{S8 Comparison of volume change rate estimates of NPI and SPI}

A comparison of our results with published volume change rate results of NPI and SPI based on remote sensing data is given in Table S11. A comparison of our 2012-2016 volume change rates with the results of Foresta et al. (2018) for the glacier basins and glacier subsets they use is given in Table S12.

\section{References}




\section{S1 TanDEM-X data}

Table S1. Specifications of the TanDEM-X Raw DEMs processed over NPI. Here two full coverages were achieved in summer 2012 (May 2011 on the termini of the western glaciers) and in December 2015. The acquisition time is approximately 6:02 (local time) (UTC-4h). DT: datatake; D: descending orbit; HoA: height of ambiguity; Look ang.: mid-range look angle. Posting long.: posting in longitude in arcsec; the posting in latitude is always 0.4 arcsec. The footprint of each scene within the mosaic, identified through an index, is shown in the maps of Fig. S1. * Experimental acquisitions, not part of the TanDEM-X mission operational plan.

\begin{tabular}{lllllllll}
\hline DT ID & $\begin{array}{l}\text { Acquisition } \\
\text { date }\end{array}$ & $\begin{array}{l}\text { Length } \\
{[\mathrm{km}]}\end{array}$ & $\begin{array}{l}\text { Rel. orbit / } \\
\text { direction }\end{array}$ & Beam & $\begin{array}{l}\text { Look } \\
\left.\text { ang. }{ }^{\circ}\right]\end{array}$ & HoA [m] & $\begin{array}{l}\text { Posting } \\
\text { long. ["] }\end{array}$ & $\begin{array}{l}\text { Scene } \\
\text { index }\end{array}$ \\
\hline 1020455 & $28 / 05 / 2011$ & 93 & $35 / \mathrm{D}$ & A1 050 & 40.6 & 48.4 & 0.4 & 1 \\
1058596 & $05 / 02 / 2012$ & 149 & $35 / \mathrm{D}$ & A1 040 & 38.4 & 89.8 & 0.4 & 2 \\
1057982 & $16 / 02 / 2012$ & 142 & $35 / \mathrm{D}$ & A1 030 & 36.1 & 89.7 & 0.4 & 3 \\
\hline $1327457^{*}$ & $03 / 12 / 2015$ & 91 & $35 / \mathrm{D}$ & strip 012 & 41.0 & 59.0 & 0.4 & 4 \\
$1327455^{*}$ & $14 / 12 / 2015$ & 146 & $35 / \mathrm{D}$ & strip 011 & 39.2 & 56.0 & 0.4 & 5 \\
$1327456^{*}$ & $08 / 12 / 2015$ & 146 & $111 / \mathrm{D}$ & strip 004 & 23.9 & 33.4 & 0.4 & 6 \\
$1327454^{*}$ & $19 / 12 / 2015$ & 115 & $111 / \mathrm{D}$ & strip 003 & 21.4 & 31.0 & 0.4 & 7 \\
\hline
\end{tabular}

Table S2. Specifications of the TanDEM-X Raw DEMs processed over SPI. Here two full coverages were achieved in summer 2012 and in December 2015. A further partial coverage was achieved in December 2011. The acquisition time is between 5:54 and 6:03 (local time) (UTC-4h). DT: datatake; D: descending orbit; HoA: height of ambiguity; Look ang.: mid-range look angle. Posting long.: posting in longitude in arcsec; the posting in latitude is always 0.4 arcsec. The footprint of each scene within the mosaic, identified through an index, is shown in the maps of Fig. S1. * Experimental acquisitions, not part of the TanDEM-X mission operational plan.

\begin{tabular}{lllllllll}
\hline DT ID & $\begin{array}{l}\text { Acquisition } \\
\text { date }\end{array}$ & $\begin{array}{l}\text { Length } \\
{[\mathrm{km}]}\end{array}$ & $\begin{array}{l}\text { Rel. orbit } ~ \\
\text { direction }\end{array}$ & Beam & $\begin{array}{l}\text { Look } \\
\left.\text { ang. }{ }^{\circ}\right]\end{array}$ & HoA [m] & $\begin{array}{l}\text { Posting } \\
\text { long. ["] }\end{array}$ & $\begin{array}{l}\text { Scene } \\
\text { index }\end{array}$ \\
\hline 1057982 & $16 / 02 / 2012$ & 136 & $35 / \mathrm{D}$ & A1 030 & 36.1 & 88.8 & 0.4 & 1 \\
1057647 & $22 / 02 / 2012$ & 102 & $126 / \mathrm{D}$ & A1 080 & 46.2 & 119.4 & 0.4 & 2 \\
1057028 & $04 / 03 / 2012$ & 200 & $126 / \mathrm{D}$ & A1 070 & 44.5 & 112.2 & 0.4 & 3 \\
1055763 & $26 / 03 / 2012$ & $146 ; 178$ & $126 / \mathrm{D}$ & A1 060 & 42.6 & 105.7 & $0.4 ; 0.4$ & $4 ; 5$ \\
1056403 & $15 / 03 / 2012$ & $157 ; 107$ & $126 / \mathrm{D}$ & A1 050 & 40.6 & 99.6 & $0.4 ; 0.6$ & $6 ; 7$ \\
1058868 & $31 / 01 / 2012$ & 164 & $126 / \mathrm{D}$ & A1 040 & 38.4 & 94.0 & 0.6 & 8 \\
\hline $1327461^{*}$ & $03 / 12 / 2015$ & 131 & $35 / \mathrm{D}$ & strip 009 & 35.3 & 49.9 & 0.4 & 9 \\
$1327453^{*}$ & $09 / 12 / 2015$ & 173 & $126 / \mathrm{D}$ & strip 014 & 44.4 & 65.4 & 0.4 & 10 \\
$1327460^{*}$ & $20 / 12 / 2015$ & 193 & $126 / \mathrm{D}$ & strip 013 & 42.8 & 62.9 & 0.4 & 11 \\
$1327459^{*}$ & $31 / 12 / 2015$ & 214 & $126 / \mathrm{D}$ & strip 012 & 41.0 & 59.3 & 0.4 & 12 \\
$1327458^{*}$ & $03 / 12 / 2015$ & 136 & $35 / \mathrm{D}$ & strip 005 & 26.4 & 38.3 & 0.6 & 13 \\
$1327462^{*}$ & $09 / 12 / 2015$ & 151 & $126 / \mathrm{D}$ & strip 010 & 37.3 & 53.6 & 0.6 & 14 \\
\hline 1041196 & $18 / 12 / 2011$ & $147 ; 179$ & $126 / \mathrm{D}$ & A1 060 & 42.6 & 81.4 & $0.4 ; 0.4$ & $16 ; 17$ \\
1041468 & $07 / 12 / 2011$ & 202 & $126 / \mathrm{D}$ & A1 050 & 40.6 & 74.6 & 0.4 & 18 \\
1040940 & $29 / 12 / 2011$ & 164 & $126 / \mathrm{D}$ & A1 040 & 38.4 & 70.8 & 0.6 & 19 \\
\hline
\end{tabular}



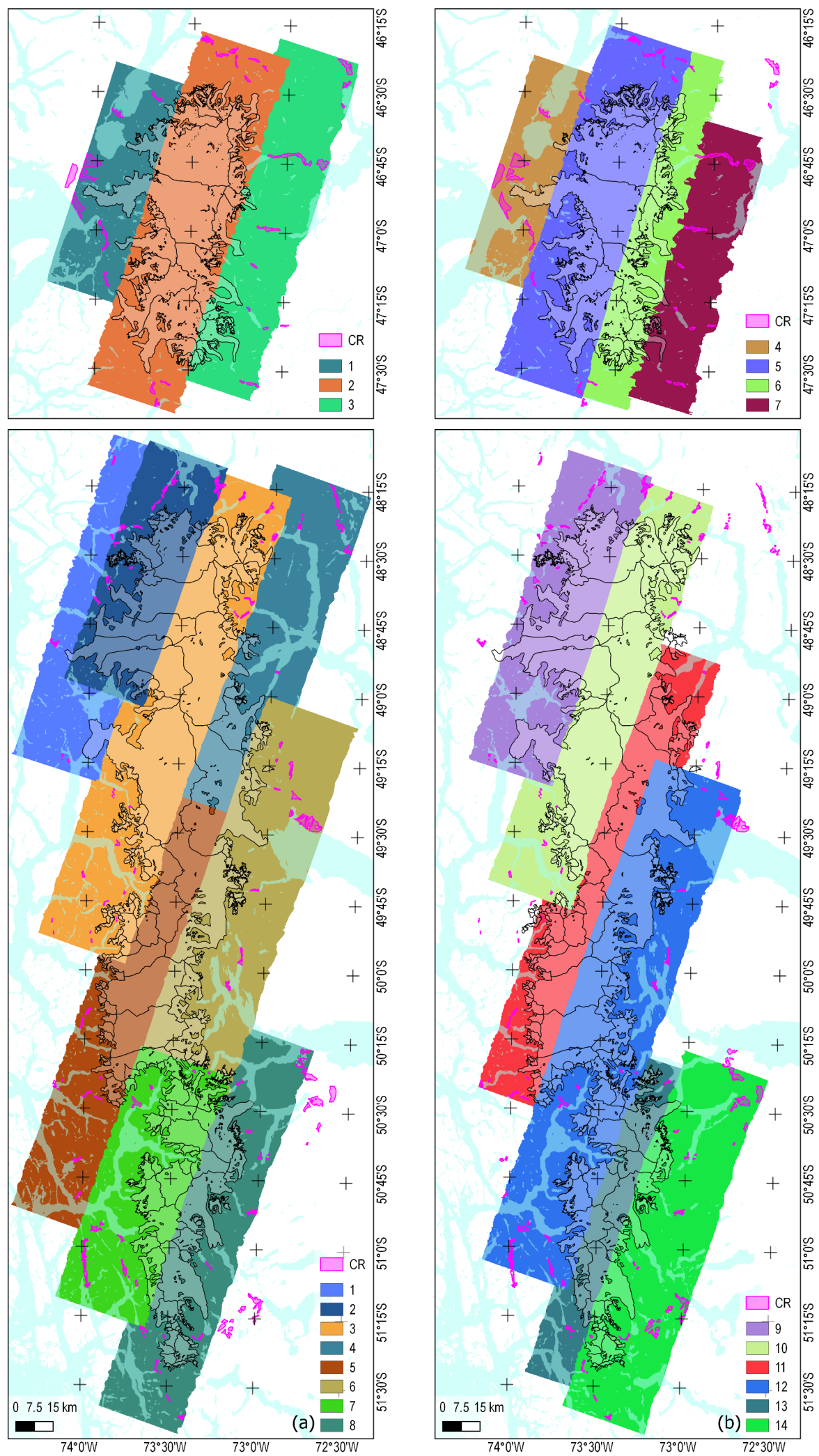

Figure S1. Footprints of the TanDEM-X Raw DEMs forming (a) the 2012 and (b) the 2015 DEM mosaics. The specifications of each Raw DEM, identified by an index, are reported in Tables S1 and S2, for NPI and SPI, respectively. Magenta: the footprints of the calibration regions (CRs) used to perform the DEM coregistration (Sect. 3.1.2). 


\section{S2 SRTM data}

Table S3. SRTM C-band datatakes covering SPI and NPI. The table reports orbit number, datatake index, orbital direction (A: ascending, D: descending) and the sub-swaths used to compute the average backscattering $\bar{\sigma}^{0}$ (Sect. 3.2.2). The acquisition time refers to the start of the datatake (Seal and Rogez, 2000).

\begin{tabular}{lcclc}
\hline Orbit n. & DT & Dir. & Sub-swaths & Acq. loc. time (UTC-4h) \\
\hline 10 & 200 & D & 4 & $12 / 02 / 200004: 04$ \\
28 & 230 & A & 4 & $13 / 02 / 200006: 56$ \\
41 & 190 & D & 1 & $14 / 02 / 200002: 04$ \\
44 & 230 & A & 3,4 & $14 / 02 / 200006: 42$ \\
57 & 190 & D & 1,2 & $15 / 02 / 200001: 50$ \\
60 & 230 & A & $2,3,4$ & $15 / 02 / 200006: 29$ \\
73 & 190 & D & $1,2,3,4$ & $16 / 02 / 200001: 37$ \\
76 & 230 & A & $1,2,3,4$ & $16 / 02 / 200006: 16$ \\
89 & 190 & D & $1,2,4$ & $17 / 02 / 200001: 24$ \\
92 & 230 & A & $1,2,3,4$ & $17 / 02 / 200006: 02$ \\
105 & 200 & D & $2,3,4$ & $18 / 02 / 200001: 10$ \\
108 & 230 & A & 2,4 & $18 / 02 / 200005: 49$ \\
121 & 200 & D & $1,3,4$ & $19 / 02 / 200000: 57$ \\
124 & 230 & A & $1,2,3,4$ & $19 / 02 / 200005: 35$ \\
137 & 200 & D & $1,2,3,4$ & $20 / 02 / 200000: 43$ \\
140 & 230 & A & 1,2 & $20 / 02 / 200005: 22$ \\
153 & 200 & D & 3,4 & $21 / 02 / 200000: 30$ \\
156 & 240 & A & 1 & $21 / 02 / 200005: 09$ \\
\hline
\end{tabular}



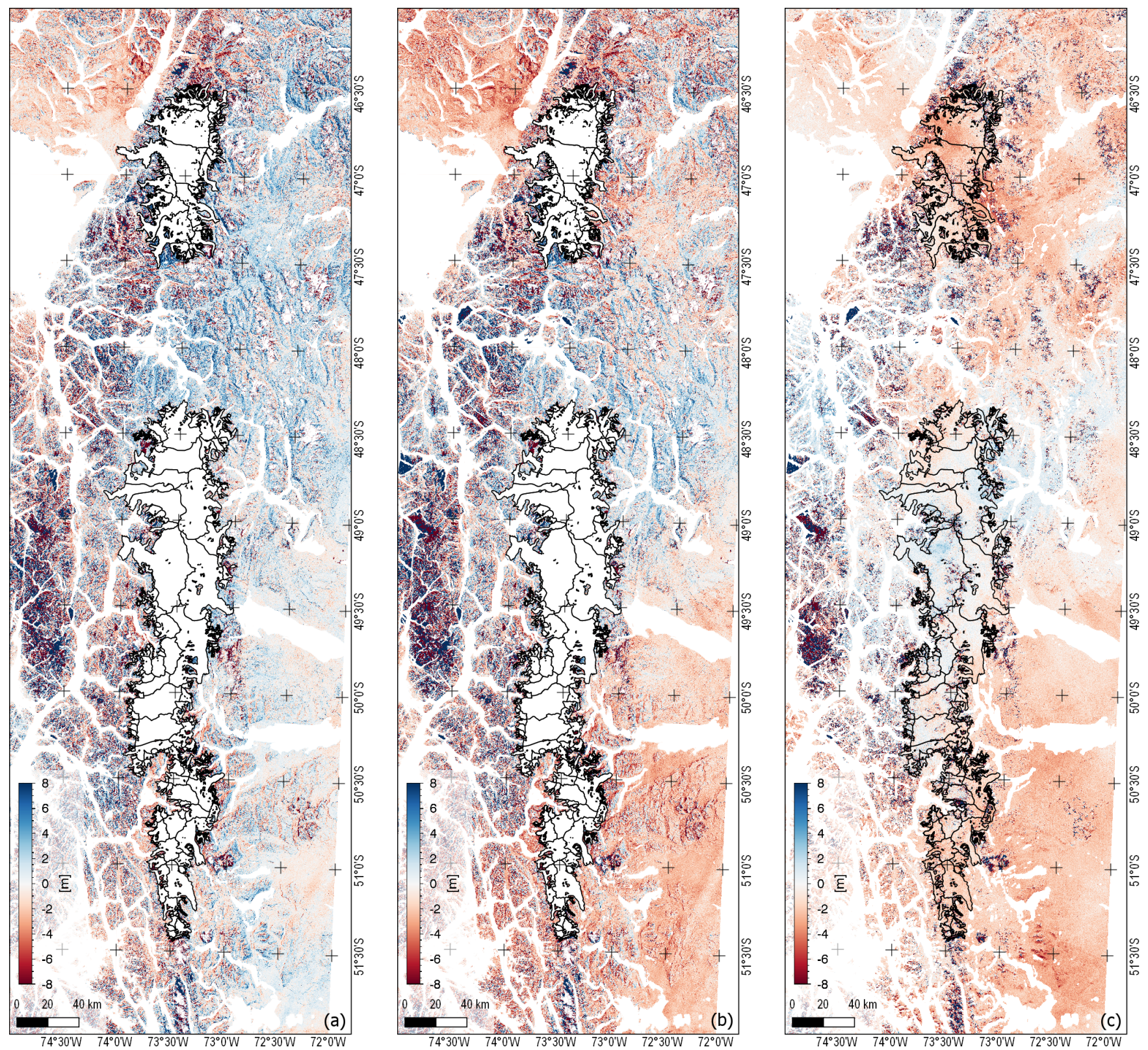

Figure S2. DEM differences at 1 arcsec used to evaluate the two different SRTM data sets. (a) $\Delta h=$ TDM - NASADEM, (b) $\Delta h=$ TDM SRTMGL1 and (c) $\Delta h=$ NASADEM - SRTMGL1. TDM: TanDEM-X global DEM used as reference elevation (Sect. 3.1.1). The statistics measured on stable terrain on maps (a) and (b) are reported in Table S4.

Table S4. Statistics of the DEM difference between the TDM global DEM and the two SRTM products. The TDM global DEM was scaled to the 1 arcsec posting of the NASADEM and SRTMGL1 DEMs. Approximately 100 million samples were selected on the stable terrain (no ice, no water) visible in Fig. S2, with terrain slope below $40^{\circ}$ and a elevation difference $|\Delta h| \leq 20 \mathrm{~m}$ to avoid artefacts (e.g. phase unwrapping errors).

\begin{tabular}{lccc}
\hline$\Delta h$ & Mean & Std. dev. & RMS \\
\hline TDM - NASADEM & $0.194 \mathrm{~m}$ & $3.832 \mathrm{~m}$ & $3.837 \mathrm{~m}$ \\
TDM - SRTMGL1 & $-0.982 \mathrm{~m}$ & $3.895 \mathrm{~m}$ & $4.017 \mathrm{~m}$ \\
\hline
\end{tabular}




\section{S3 DEM coregistration and SECR derivation}

Table S5. Features of the calibration regions (CRs) selected on stable terrain around NPI and SPI and used to perform DEM coregistration (Sect. 3.1.2).

\begin{tabular}{cccccc}
\hline Reg. & No. & Tot. area & Av. area & Av. elev. & Av. slope \\
\hline NPI & 36 & $183.8 \mathrm{~km}^{2}$ & $5.1 \mathrm{~km}^{2}$ & $171.1 \mathrm{~m}$ & $3.7^{\circ}$ \\
SPI & 90 & $263.8 \mathrm{~km}^{2}$ & $2.9 \mathrm{~km}^{2}$ & $106.6 \mathrm{~m}$ & $3.8^{\circ}$ \\
\hline
\end{tabular}

\section{Artefact masking}

To avoid biases of the mass balance we masked-out artefacts due to phase unwrapping, layover, shadow, etc. For each SECR a masking raster was produced according to the following subsequent steps:

1. The TDM RAW DEMs come with a flag mask (FLM) which highlights possible layover shadow, this was only initially used to get the rough position of main larger layover/shadow regions.

2. Thresholds were applied on the samples of the SECR, these were discarded when $\Delta h<-72 \mathrm{~m}$ or $\Delta h>+72 \mathrm{~m}$ for the epoch 2000-2012 and when $\Delta h<-28 \mathrm{~m}$ or $\Delta h>+28 \mathrm{~m}$ for the epoch 2012-2015. The eliminated samples are residual small phase unwrapping errors and noise peaks, mostly found on layover and shadow regions. Regions of significant physical change (i.e. glacier termini) in excess of the thresholds were not included and treated separately (see point no. 4).

3. A morphological operator of closing $($ size $5 \times 5)$ followed by a median filter $($ size $5 \times 5)$ was applied on the mask raster in order to remove noise from the mask generated by the thresholding, hence removing isolated mask pixels in the mask.

4. Visual inspection of the mask raster and further manual correction. 


\section{S4 Seasonal correction}

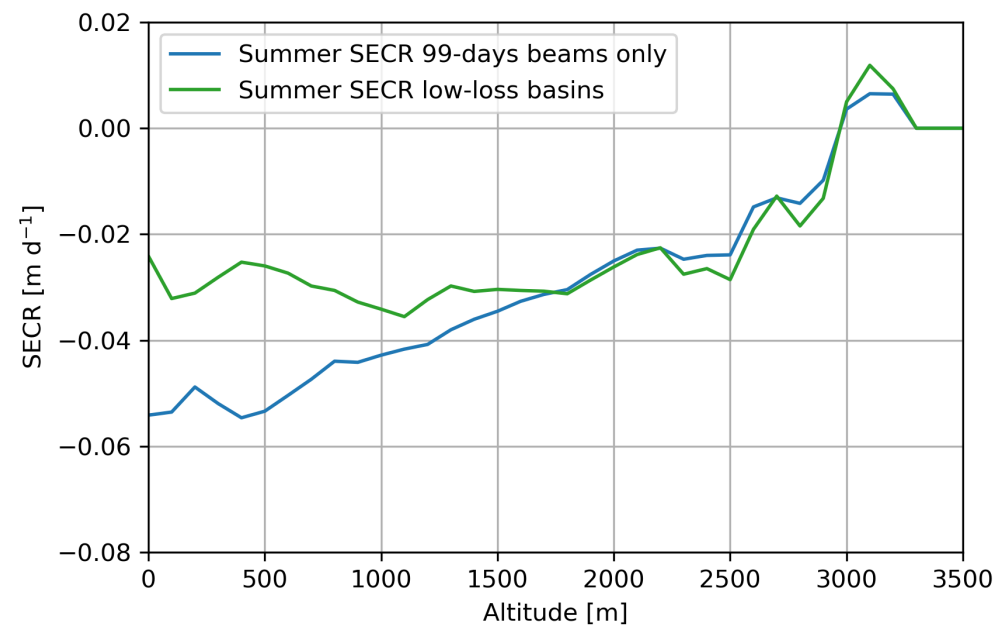

Figure S3. Hypsometric averages extracted from different sub-regions of the summer 2011/2012 SECR (Fig. 8) and used to perform the seasonal correction (Sect. 3.1.3). The blue curve includes all glaciers covered by the two beams featuring a time span of 99 days. The green curve includes all three beams (99 and 33 days) but only selected low-loss glaciers (Perito Moreno, Grey, Tyndall, HPS 13, Europa, Penguin, Guilardi and part of the accumulation area of Pio XI) 

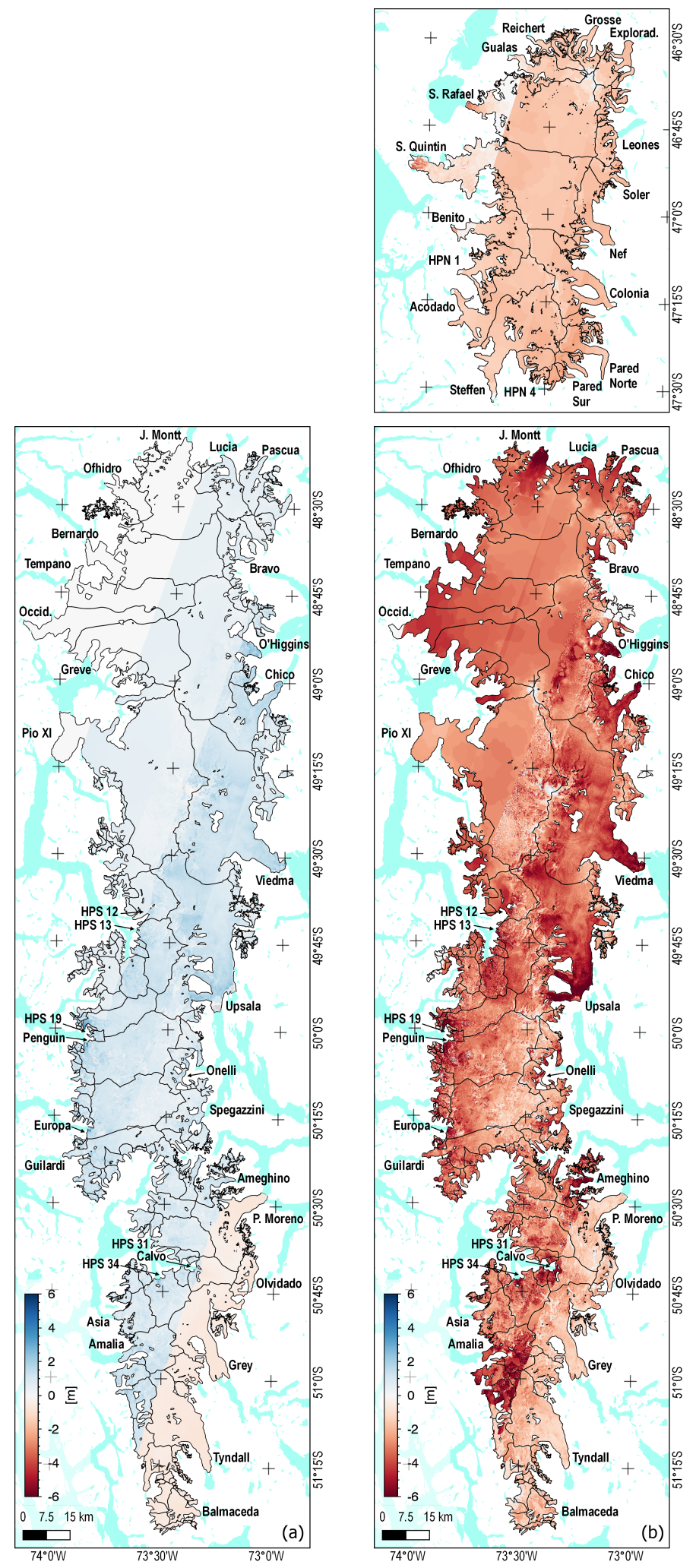

Figure S4. Seasonal correction (SEC in metres) added to the original SEC maps for deriving SECR maps that account for full temporal coverage of the epochs (a) 2000-2012 and (b) 2012-2016. 
Estimation of mass balance gradients for Jorge Montt, S. Rafael and S. Quintin glaciers for the seasonal correction of surface elevation change

Elevation gradients of surface mass balance (SMB) for summer and the full year, derived from multi-year time series of climate data and ablation measurements on Perito Moreno Glacier (Stuefer et al., 2007), are used for estimating seasonal differences of SMB-related SEC rates (SECR) of Jorge Montt Glacier (located at the NW-corner of SPI) and for the termini of S. Rafael and S. Quintin glaciers (as well as small part near the front of Benito Glacier) on the west coast of NPI.

The following gradient of specific net mass balance, $b_{n}$, in the ablation area of Perito Moreno Glacier was derived from field data: $\Delta b_{n} / z=0.0122 \mathrm{~m} \cdot(\mathrm{ma})^{-1}$ w.e. (water equivalent).

In order to assess the applicability of the seasonal differences of the Perito Moreno SMB gradient for the four glaciers mentioned above we performed the following checks.

\section{Estimation of the SMB gradient for Jorge Montt Glacier}

Due to the lack of data on the mass balance of Jorge Montt Glacier, we derive the SMB gradient from numbers reported for Chico Glacier, located on the east side of northern SPI.

- Rivera (2004) reports for Chico Glacier a mean $\Delta b_{n} / z=0.013 \mathrm{~m} \cdot(\mathrm{ma})^{-1}$ over the total elevation range. The (close to linear) value in the ablation area is: $\Delta b_{n} / z=0.015 \mathrm{~m} \cdot(\mathrm{ma})^{-1}$.

- Bravo et al. (2019) report the following ratio of the west/east temperature lapse rate (LR) at the transect Occidental to O'Higgins glaciers across northern SPI: LR(west) $=0.76 \mathrm{LR}$ (east).

- Chico Glacier is adjacent to O'Higgins Glacier. Using the balance gradient of the ablation area of Chico Glacier and the LR west/east ratio of 0.76 results in the following SMB gradient for Jorge Montt Glacier: $\Delta b_{n} / z$ (west) $=0.0114$ $\mathrm{m} \cdot(\mathrm{ma})^{-1}$.

\section{Estimation of the SMB gradient for western outlet glaciers of NPI}

- Mean ELA $\left(b_{n}=0\right)$ of NPI west (S. Rafael, S. Quintin): $1200 \mathrm{~m}$ a.s.l. (Rivera et al., 2007).

- SMB on NPI western outlet glaciers on the terminus near the front (about $50 \mathrm{~m}$ a.s.l.): $b_{n} \approx 14 \mathrm{ma}^{-1}$ (Schaefer et al., 2013).

- Resulting balance gradient for the ablation area: $\Delta b_{n} / z=0.01217 \mathrm{~m} \cdot(\mathrm{ma})^{-1}$.

\section{Conclusion}

The balance gradient for NPI western outlet glaciers, derived from modelled SMB data of Schaefer et al. (2013), agrees with the multi-year SMB gradient of Moreno Glacier. The difference to the estimated balance gradient for Jorge Montt Glacier, deduced from the gradient of Chico Glacier, taking into account the different west/east lapse rates, is also small. This supports the approach of using the Moreno Glacier mass balance gradient and seasonal/annual ratio for deriving the SECR seasonal correction of the four glaciers. 

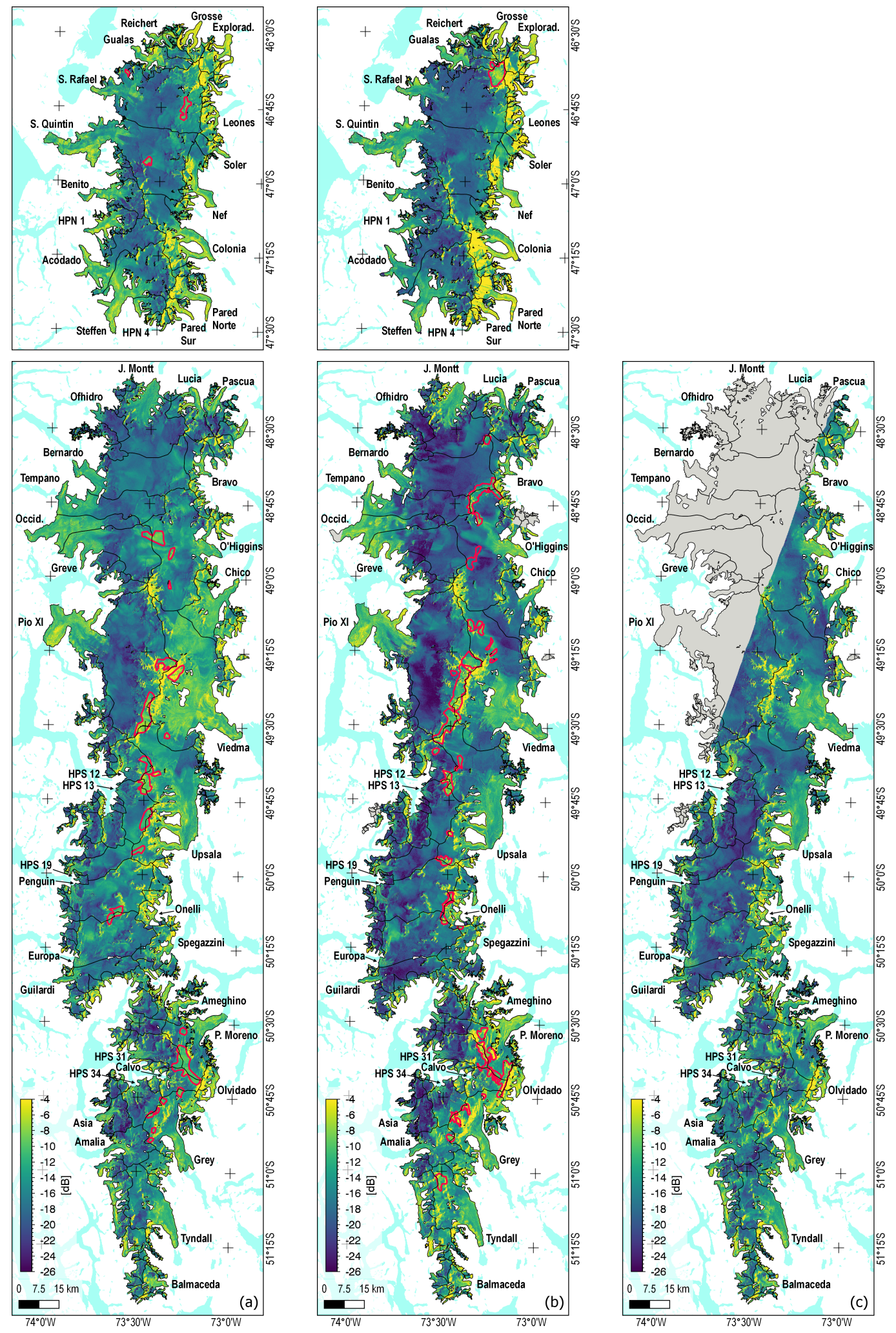

Figure S5. Mosaics of backscattering coefficient $\sigma^{0}$ for all TanDEM-X coverages: (a) Summer 2012, (b) December 2015 and (c) December 2011. Red outlines: regions with high probability of signal penetration, individually taken into account in the error budget. Grey: no coverage. 

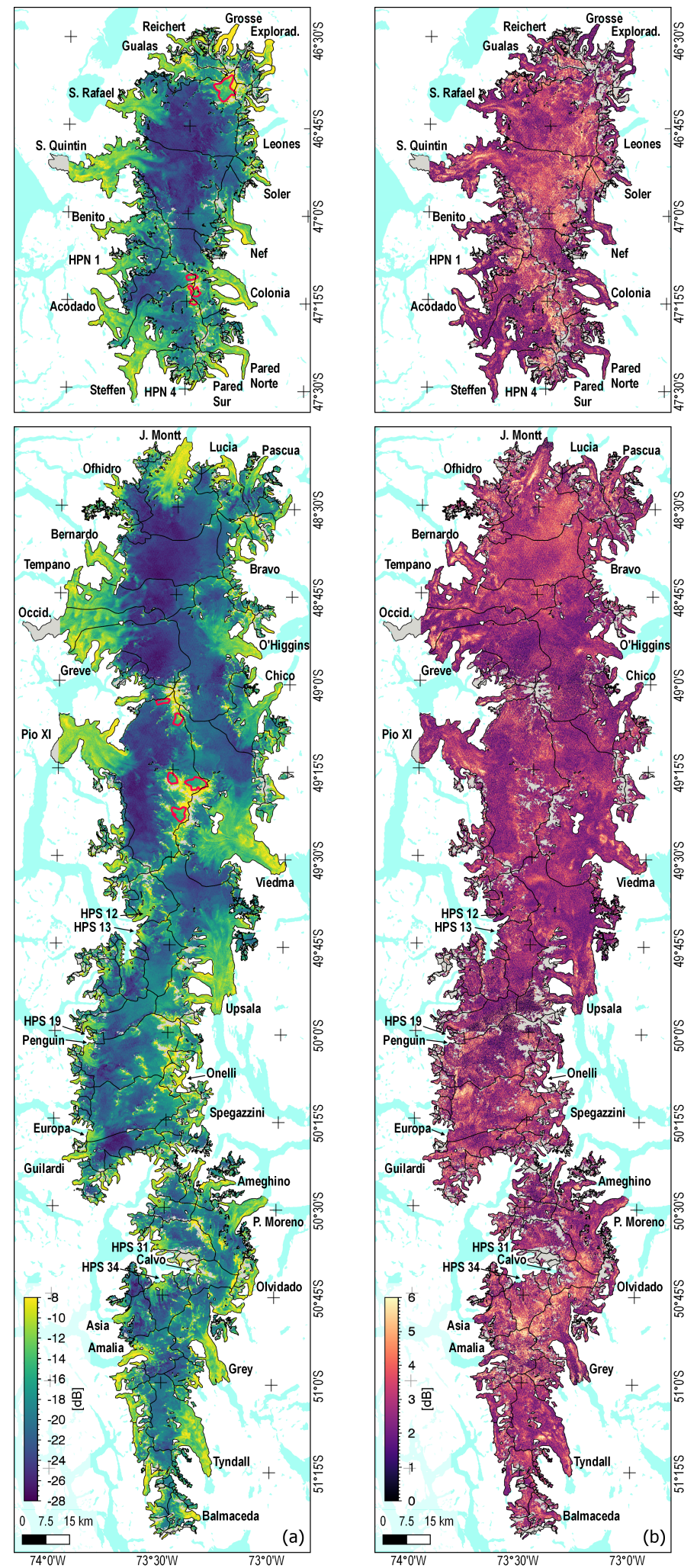

Figure S6. SRTM backscattering (a) mean $\bar{\sigma}^{0}$ and (b) standard deviation, computed pixelwise on all sub-swaths listed in Table S3. Red outlines: regions with high probability of signal penetration, individually taken into account in the error budget. Grey: no coverage. 
Table S6. Percentage of accumulation area included in the critical outlined regions and weighted mean of the penetration offset $\Delta h_{p}$ assigned to them.

\begin{tabular}{|c|c|c|c|c|}
\hline & \multicolumn{2}{|c|}{ NPI } & \multicolumn{2}{c|}{ SPI } \\
\hline DEM data set & \% of acc. area & Mean $\Delta h_{p}[\mathrm{~m}]$ & \% of acc. area & Mean $\Delta h_{p}[\mathrm{~m}]$ \\
\hline \hline SRTM & 1.6 & 3.0 & 0.5 & 1.5 \\
\hline TDM Summer 2012 & 0.9 & 2.0 & 0.9 & 2.0 \\
\hline TDM December 2015 & 1.1 & 3.0 & 2.4 & 3.1 \\
\hline
\end{tabular}

\section{Estimation of penetration height offsets for error budget}

Studies on TanDEM-X elevation bias due to signal penetration $\left(\Delta h_{p}\right)$ in dry snow, focusing at ice sheets, show snow microstructure as dominating cause of variations on $\Delta h_{p}$ (Rizzoli et al., 2017). The relationships over ice sheets are not applicable to the Patagonian icefields where the accumulation rates are up to two orders of magnitude larger and meltwater is present in firn layers throughout the year with dry snow on top during winter (Rivera, 2004). Therefore we derived an empirical relation for estimating $\Delta h_{p}$ from observed backscattering coefficients, $\sigma^{0}$, based on a TDM data set of NPI featuring well separated wet and dry snowpack clusters (Fig. S7).

The scatterplot in Fig. S7 shows the apparent change in elevation, $\Delta h=h_{\mathrm{w}}-h_{\mathrm{s}}$, between TDM repeat DEMs acquired at the end of winter (Date 1: 2 September 2013, 19:46 local time, UTC-4h) and in summer (Date 2: 1 January 2014, same time) for a sub-region of NPI, extending over an area of about $500 \mathrm{~km}^{2}$ and covering altitudes between $1150 \mathrm{~m}$ and $1550 \mathrm{~m}$. The $\mathrm{x}$-axis shows the $\sigma^{0}$ of Date 1. A first cluster CL 1 corresponds to the lower section of the accumulation area (mean elevation $h=$ $1260 \mathrm{~m}$ ) and to melting snow surfaces (mean $\sigma^{0}=-17.8 \mathrm{~dB}$ ), a second cluster CL 2 corresponds to the upper section and to dry snow $\left(h=1460 \mathrm{~m} ; \sigma^{0}=-9.8 \mathrm{~dB}\right.$ ). Date 1 coincided with a period of heavy precipitation, with the zero degree isotherm at about $1350 \mathrm{~m}$ altitude. The backscatter values on Date $2\left(\right.$ mean $\sigma^{0}=-17.8 \mathrm{~dB}$ ) indicate melting snow surfaces at all elevations. Assuming the temporal change in $h$ between the two dates being of the same magnitude for all points of the scatterplot, and assuming zero penetration for CL 1 on Date 1 and for all points on Date 2 results in the following ratio between $\Delta h$ [m] and $\sigma^{0}$ $[\mathrm{dB}]$ of the cluster centres: $f_{h p}=\Delta h /\left[\sigma^{0}(\mathrm{CL} 1-\mathrm{CL} 2)\right]=-0.50$. This coefficient is used for estimating the penetration height offset for critical regions (red outlines in Fig. S5) with the following relation: $\Delta h_{p}=f_{h p} \cdot\left(\sigma_{\mathrm{ref}}^{0}-\sigma_{\mathrm{ds}}^{0}\right) \cdot \sigma_{\text {ref }}^{0}$ is the reference value for zero penetration, $\sigma_{\mathrm{ds}}^{0}$ refers to snow pack with increased backscatter due to a layer of dry snow on top. The mid-range look angle for the TDM track is $36.2^{\circ}$ on Date 1 and $37.2^{\circ}$ on Date 2 . The mid-range look angles of the tracks covering most of the red outlines in the TDM data of 2012 and 2015 range on NPI from $38.4^{\circ}$ to $39.2^{\circ}$, on SPI from $37.3^{\circ}$ to $44.5^{\circ}$. For a volume scattering medium the difference in $\sigma^{0}$ due to the maximum difference in look angle between the reference data set and any of the outlined regions would amount to $0.7 \mathrm{~dB}$. Allowing for some uncertainty in this relation, we use $\sigma_{\text {ref }}^{0}$ and $f_{h p}$ as described above for estimating the penetration bias from mean $\sigma^{0}$ of each outlined region. The resulting $\Delta h_{p}$ values are rounded to the nearest integer. These values, together with an additional height offset of $0.1 \mathrm{~m}$ assigned to the rest of the accumulation area, were used to estimate the systematic error due to signal penetration for each DEM mosaic (Sect. 3.3.3).

For SRTM the $\sigma^{0}$ values of are slightly reduced compared to melting snow over a few sites. In order to account for the frequency dependence in penetration, we use a factor of two for estimating the C-band penetration of SRTM with the relation applied for the TDM data. Experimental data show for dry snow about double penetration depth for C-band compared to X-band (Rott et al., 1993).

Table S6 lists the percentage of the NPI and SPI accumulation areas included in the critical outlined regions and provides the mean penetration offsets on these outlines $\left(\Delta h_{p}\right.$ weighted on the corresponding area). Depending on the icefield and date, the percentage of accumulation area potentially prone to penetration ranges from $0.9 \%$ to $2.4 \%$. Wide-spread surface melt dominated in the SAR scenes selected for this study, nevertheless a default $\Delta h_{p}=0.1 \mathrm{~m}$ was assigned to the rest of the accumulation area when computing the systematic error due to penetration (Sect. 3.3.3). 


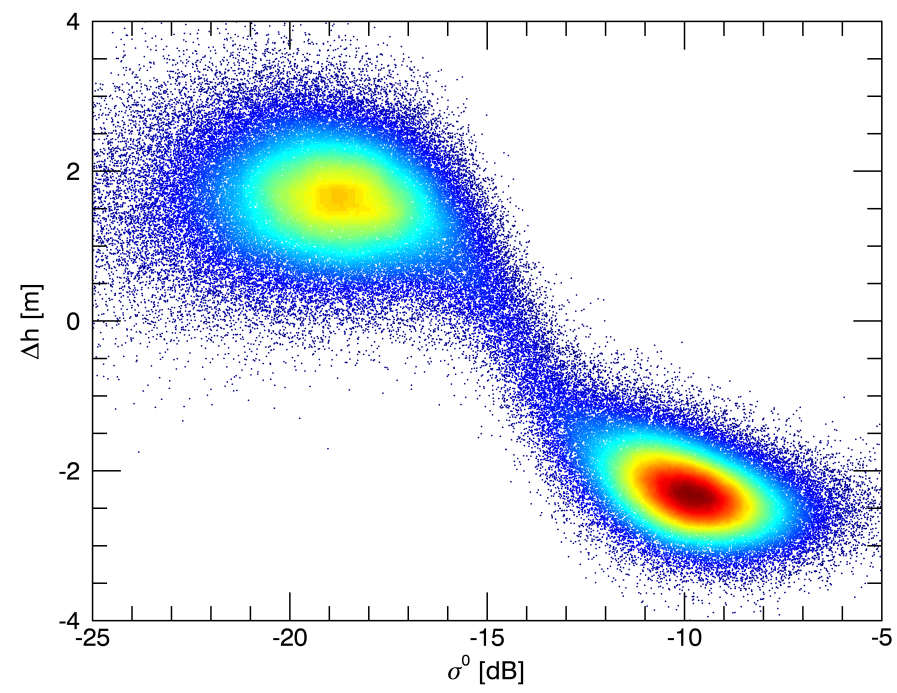

Figure S7. Scatterplot of apparent elevation differences $\Delta h=h_{\mathrm{W}}-h_{\mathrm{S}}$ (2 Sept. 2013 minus 1 Jan. 2014) on the NPI plateau at elevations between 1150 and $1550 \mathrm{~m}$ versus $\sigma^{0}$ of 2 Sept. 2013. From Abdel Jaber (2016). 

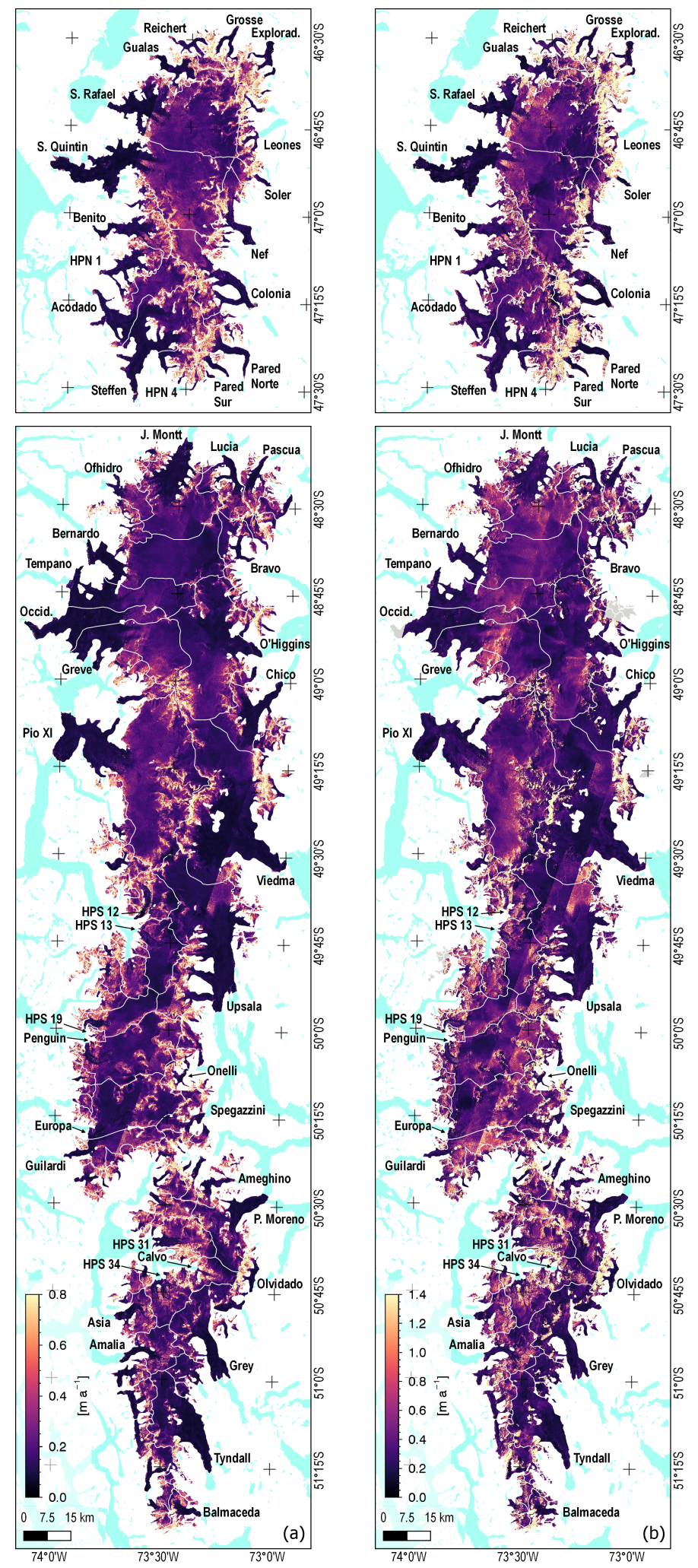

Figure S8. Random error of the SECR maps of (a) 2000-2012 and (b) 2012-2016 obtained as described in Sect. 3.3.1. 

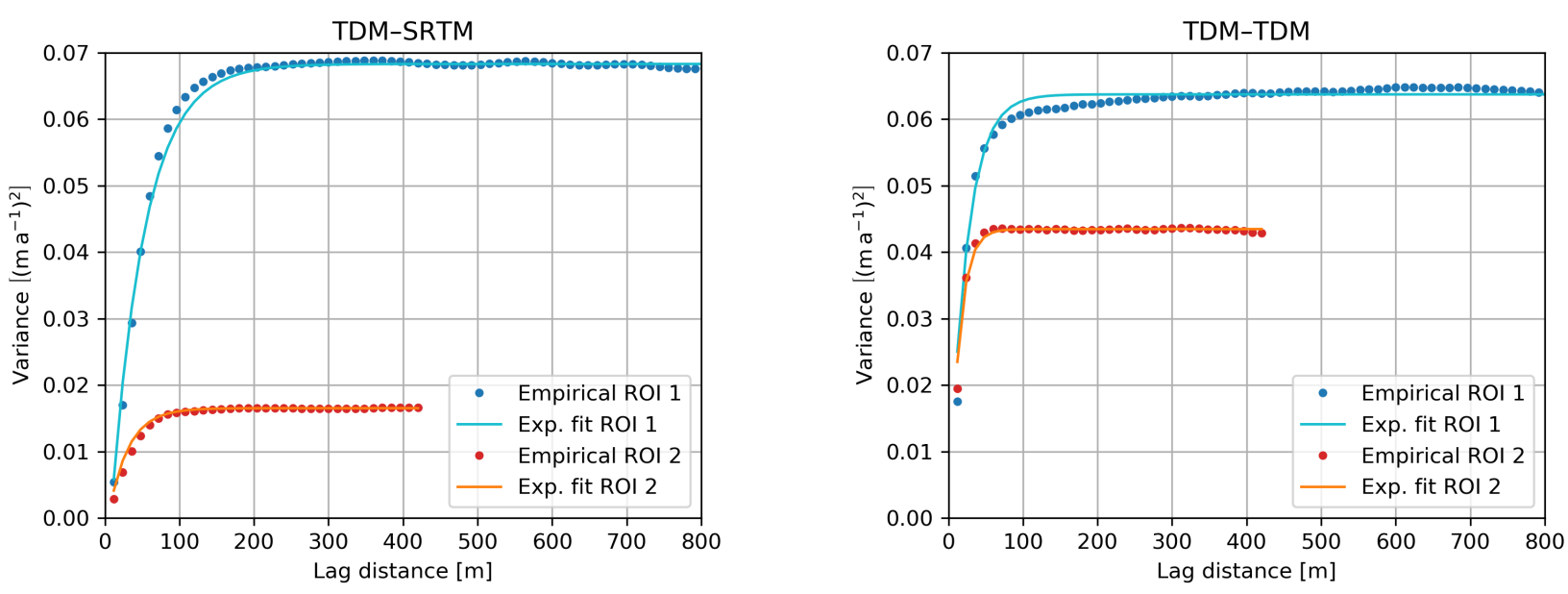

Figure S9. Empirical omnidirectional semivariograms and corresponding exponential model fits computed from a TDM-SRTM SECR and a TDM-TDM SECR for two ice-free regions of interest (ROIs) with different topography (Sect. 3.3.2). ROI 1: hilly terrain with slope distribution similar to the icefields. ROI 2: flat terrain with slope distribution similar to the calibration regions (Sect. 3.1.2). The range, nugget and sill of the fitted exponential semivariogram model are reported in Table S7.

Table S7. Parameters of the exponential semivariogram model fitted to the four empirical semivariograms shown in Fig. S9. The given uncertainties are meant as $1-\sigma$.

\begin{tabular}{llll}
\hline & Range [m] & Sill $\left[\left(\mathrm{ma}^{-1}\right)^{2}\right]$ & Nugget $\left[\left(\mathrm{ma}^{-1}\right)^{2}\right]$ \\
\hline ROI 1 TDM-SRTM & $135.3 \pm 2.8$ & $0.082 \pm 0.001$ & $0.013 \pm 0.001$ \\
ROI 1 TDM-TDM & $71.3 \pm 3.7$ & $0.064 \pm 0.003$ & $0.001 \pm 0.003$ \\
ROI 2 TDM-SRTM & $79.6 \pm 5.6$ & $0.019 \pm 0.001$ & $0.003 \pm 0.001$ \\
ROI 2 TDM-TDM & $38.5 \pm 3.3$ & $0.051 \pm 0.005$ & $0.007 \pm 0.005$ \\
\hline
\end{tabular}

Table S8. Mean of the four systematic error components and mean of the total SECR systematic error computed on the entire icefield for both epochs according to Sect. 3.3.3. $\varepsilon_{\text {reg }}$ : coregistration error; $\varepsilon_{\text {pen }}$ : radar signal penetration error; $\varepsilon_{\text {add }}$ : additional bulk error; $\varepsilon_{\text {seas }}$ : seasonal correction error; $\varepsilon$ : total systematic error.

\begin{tabular}{ccccccc}
\hline Data set & $\Delta t[\mathrm{a}]$ & $\overline{\varepsilon_{\text {reg }}}\left[\mathrm{ma}^{-1}\right]$ & $\overline{\varepsilon_{\text {pen }}}\left[\mathrm{ma}^{-1}\right]$ & $\varepsilon_{\text {add }}\left[\mathrm{ma}^{-1}\right]$ & $\overline{\varepsilon_{\text {seas }}}\left[\mathrm{ma}^{-1}\right]$ & $\bar{\varepsilon}\left[\mathrm{ma}^{-1}\right]$ \\
\hline NPI 2000-2012 & 12.0 & 0.0222 & 0.0127 & 0.0253 & $\mathrm{n} / \mathrm{a}$ & 0.0391 \\
SPI 2000-2012 & 12.0 & 0.0169 & 0.0116 & 0.0172 & 0.0088 & 0.0300 \\
NPI 2012-2016 & 4.0 & 0.0590 & 0.0373 & 0.0177 & 0.1185 & 0.1475 \\
SPI 2012-2016 & 4.0 & 0.0514 & 0.0463 & 0.0177 & 0.1043 & 0.1379 \\
\hline
\end{tabular}




\section{S7 Results}
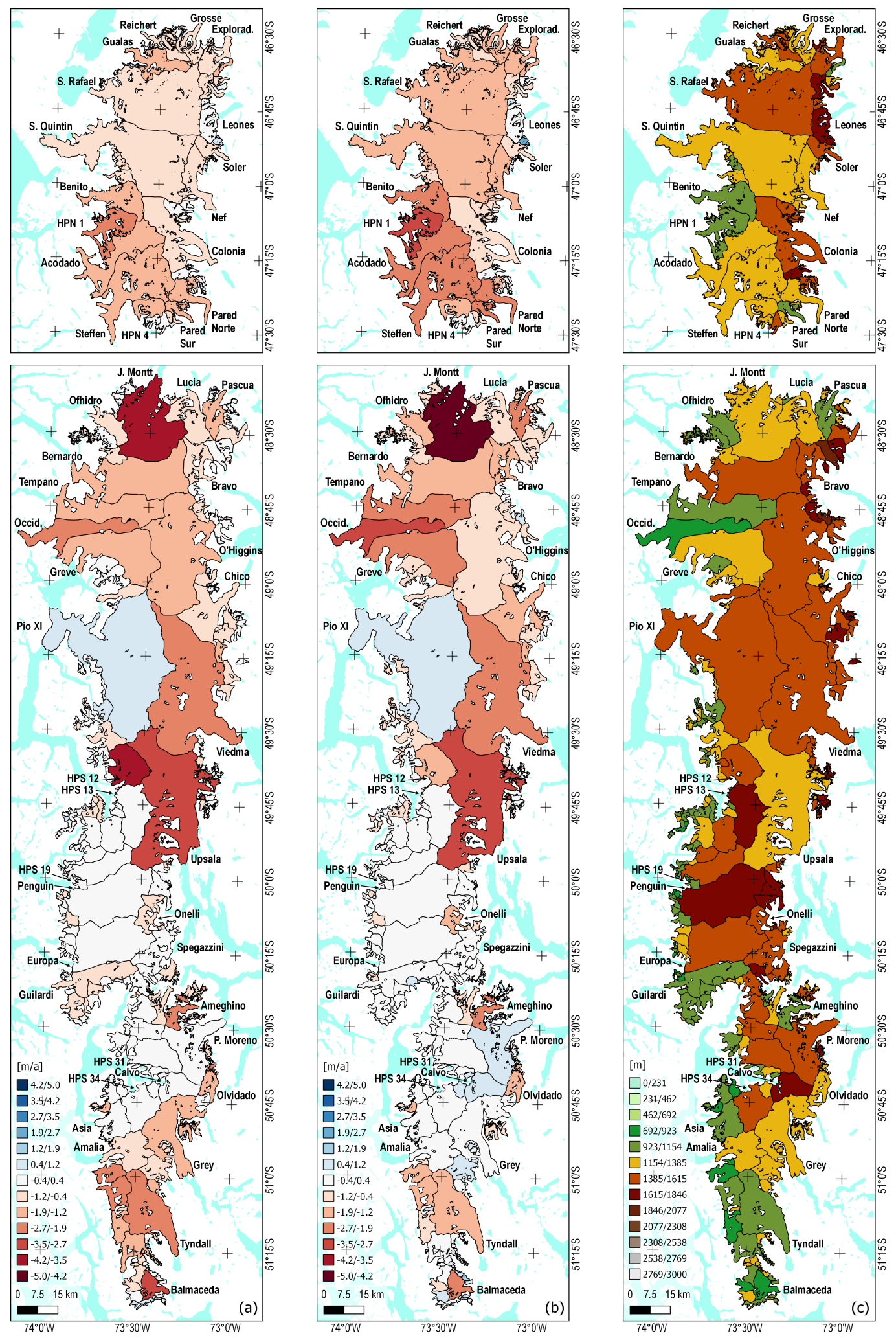

Figure S10. Average SECR per glacier basin of NPI and SPI for the two epochs (a) 2000-2012 and (b) 2012-2016. (c) Average elevation from the TDM 2012 DEM mosaic. 

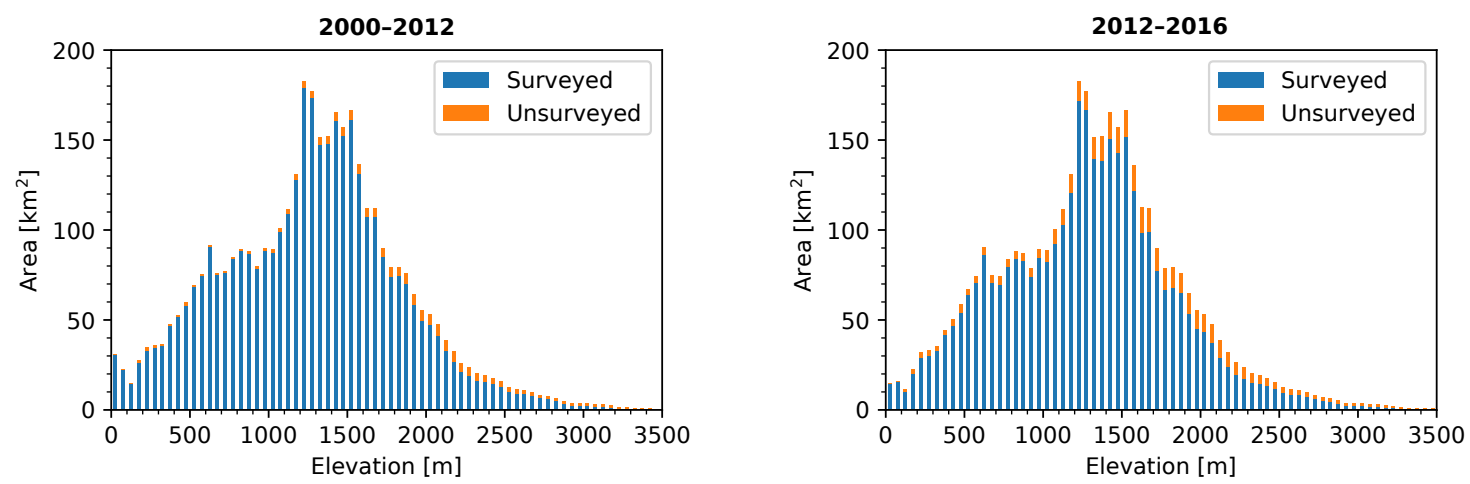

Figure S11. Hypsometry of NPI according to the reference DEM (TDM 2012/2011). The distribution of unsurveyed area in the SECR of 2000-2012 and 2012-2016 is highlighted in orange.
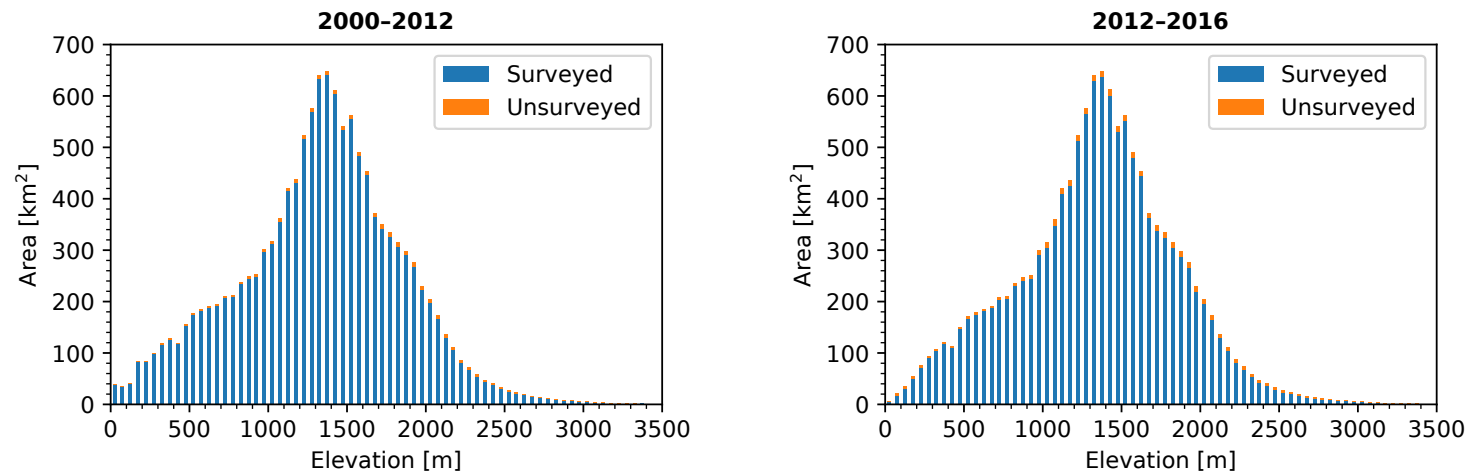

Figure S12. Hypsometry of SPI according to the reference DEM (TDM 2012). The distribution of unsurveyed area in the SECR of 2000-2012 and 2012-2016 is highlighted in orange.
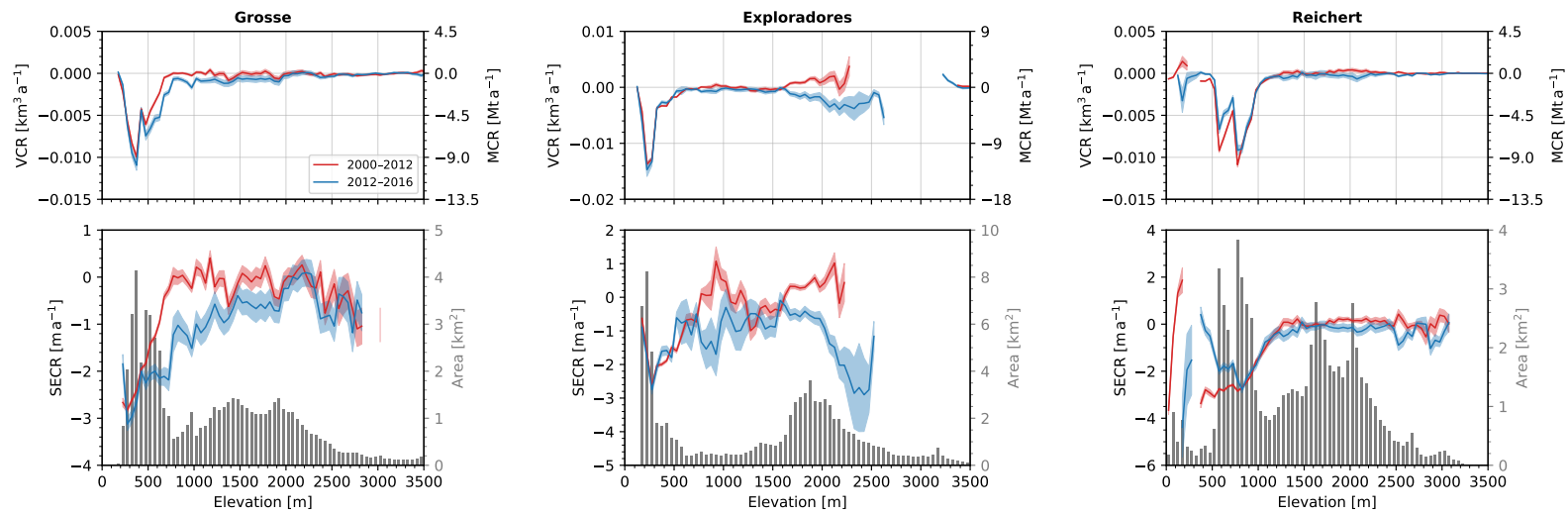

Figure S13. Surface elevation, volume and mass change rates (SECR, VCR, MCR) versus altitude in $50 \mathrm{~m}$ intervals for three more glaciers of NPI for epochs 2000-2012 (red) and 2012-2016 (blue). The hypsometric curve of 2012 is shown in grey. 

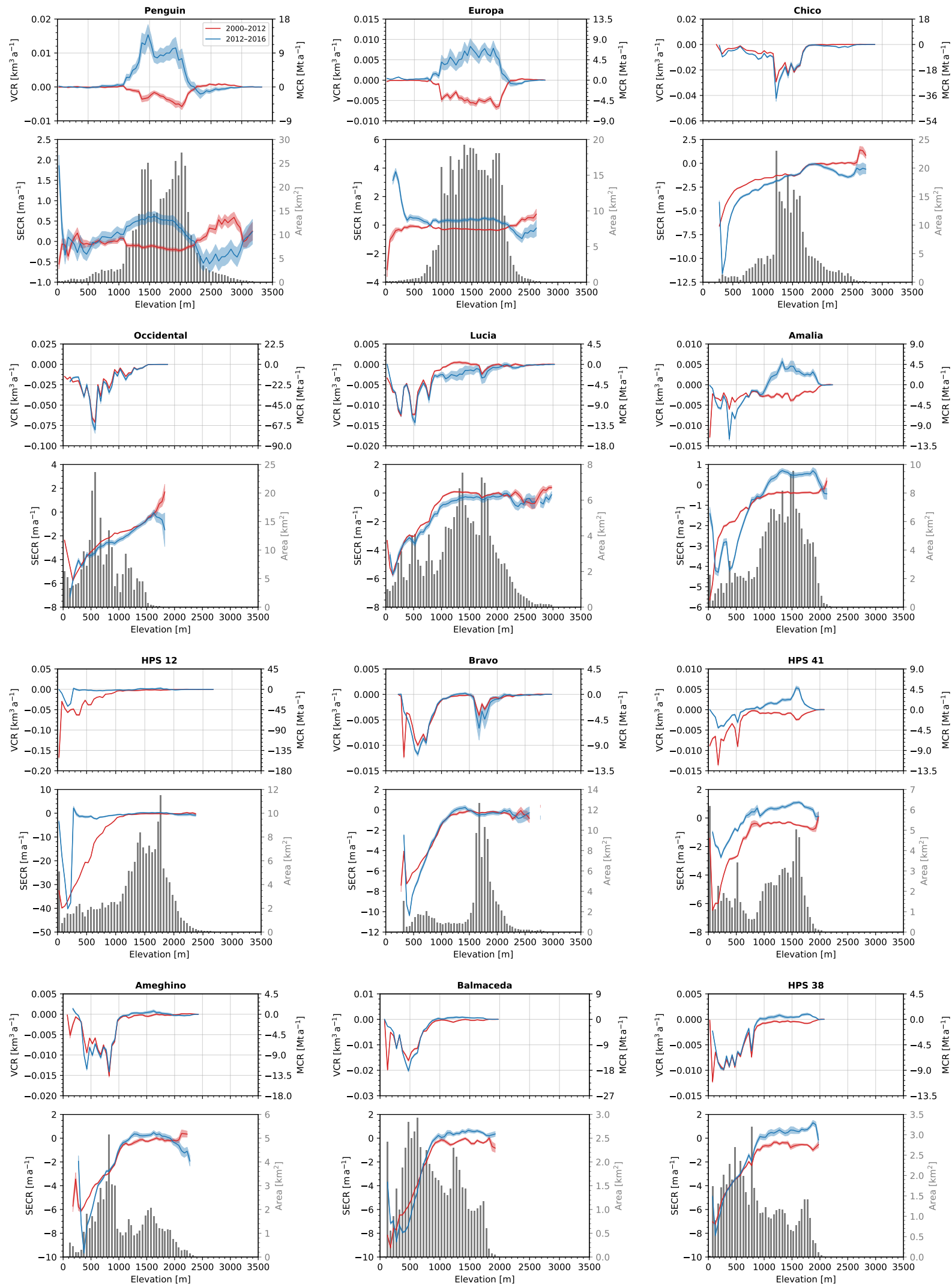
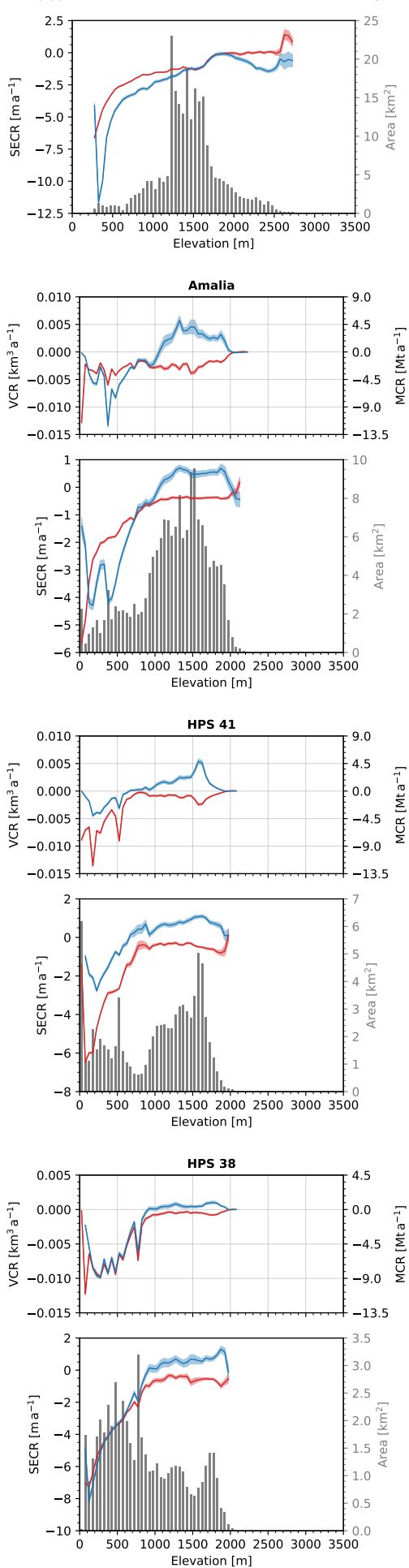

Figure S14. Surface elevation, volume and mass change rates (SECR, VCR, MCR) versus altitude in $50 \mathrm{~m}$ intervals for 12 more glaciers of SPI for epochs 2000-2012 (red) and 2012-2016 (blue). The hypsometric curve of 2012 is shown in grey. 
Table S9. Average surface elevation change rate (SECR) and volume change rate (VCR) for SPI glaciers smaller than $35 \mathrm{~km}^{2}$ and larger than $9 \mathrm{~km}^{2}$ for the two epochs. The reported area refers to the beginning of the epoch, the coverage of the SECR map is also reported. Subaqueous ice changes are not included. The list is continued from Table 3.

\begin{tabular}{|c|c|c|c|c|c|c|c|c|}
\hline \multirow[b]{2}{*}{ RGI Name } & \multicolumn{4}{|c|}{$2000-2012$} & \multicolumn{4}{|c|}{$2012-2016$} \\
\hline & $\begin{array}{r}\text { Area } \\
{\left[\mathrm{km}^{2}\right]}\end{array}$ & $\begin{array}{r}\text { Cov. } \\
{[\%]}\end{array}$ & $\begin{array}{r}\text { Average SECR } \\
{\left[\mathrm{ma}^{-1}\right]}\end{array}$ & $\begin{array}{l}\text { Volume change } \\
\qquad\left[\mathrm{km}^{3} \mathrm{a}^{-1}\right]\end{array}$ & $\begin{array}{r}\text { Area } \\
{\left[\mathrm{km}^{2}\right]}\end{array}$ & $\begin{array}{r}\text { Cov. } \\
{[\%]}\end{array}$ & $\begin{array}{r}\text { Average SECR } \\
{\left[\mathrm{ma}^{-1}\right]}\end{array}$ & $\begin{array}{l}\text { Volume change } \\
\qquad\left[\mathrm{km}^{3} \mathrm{a}^{-1}\right]\end{array}$ \\
\hline RGI-17.05044 & 35.8 & 99.9 & $0.934 \pm 0.034$ & $0.0321 \pm 0.0012$ & 34.4 & 98.3 & $0.914 \pm 0.193$ & $0.0315 \pm 0.0066$ \\
\hline RGI-17.05796 & 35.0 & 100.0 & $-0.781 \pm 0.032$ & $-0.0273 \pm 0.0011$ & 33.7 & 99.8 & $-0.551 \pm 0.181$ & $-0.0186 \pm 0.0061$ \\
\hline RGI-17.05130 & 33.5 & 100.0 & $-0.600 \pm 0.031$ & $-0.0201 \pm 0.0010$ & 33.4 & 99.5 & $-0.787 \pm 0.098$ & $-0.0262 \pm 0.0033$ \\
\hline RGI-17.04891 & 32.6 & 99.4 & $-0.298 \pm 0.035$ & $-0.0097 \pm 0.0011$ & 32.4 & 98.2 & $-0.085 \pm 0.101$ & $-0.0027 \pm 0.0033$ \\
\hline RGI-17.15796 & 31.7 & 100.0 & $-0.265 \pm 0.032$ & $-0.0084 \pm 0.0010$ & 31.4 & 99.9 & $-0.194 \pm 0.089$ & $-0.0061 \pm 0.0028$ \\
\hline RGI-17.05889 & 31.8 & 98.7 & $-0.408 \pm 0.030$ & $-0.0130 \pm 0.0010$ & 30.5 & 98.9 & $-1.026 \pm 0.182$ & $-0.0313 \pm 0.0055$ \\
\hline Grande del Torre & 30.3 & 84.4 & $-0.443 \pm 0.040$ & $-0.0134 \pm 0.0012$ & 30.1 & 94.1 & $-0.754 \pm 0.117$ & $-0.0227 \pm 0.0035$ \\
\hline Bolados & 30.0 & 85.6 & $-0.429 \pm 0.037$ & $-0.0129 \pm 0.0011$ & 28.9 & 97.9 & $-0.210 \pm 0.161$ & $-0.0061 \pm 0.0046$ \\
\hline RGI-17.05835 & 28.7 & 88.5 & $-0.161 \pm 0.036$ & $-0.0046 \pm 0.0010$ & 28.7 & 94.2 & $-0.556 \pm 0.119$ & $-0.0159 \pm 0.0034$ \\
\hline RGI-17.05338 & 28.6 & 99.8 & $-0.754 \pm 0.033$ & $-0.0215 \pm 0.0010$ & 28.2 & 99.3 & $-0.717 \pm 0.110$ & $-0.0202 \pm 0.0031$ \\
\hline Olvidado & 27.4 & 88.0 & $-1.672 \pm 0.052$ & $-0.0459 \pm 0.0014$ & 26.7 & 91.6 & $-0.960 \pm 0.096$ & $-0.0257 \pm 0.0026$ \\
\hline RGI-17.05549 & 26.4 & 99.7 & $-0.564 \pm 0.034$ & $-0.0149 \pm 0.0009$ & 26.4 & 94.9 & $-0.514 \pm 0.102$ & $-0.0136 \pm 0.0027$ \\
\hline Mayo Norte & 25.9 & 99.9 & $-0.483 \pm 0.031$ & $-0.0125 \pm 0.0008$ & 25.9 & 98.4 & $0.057 \pm 0.080$ & $0.0015 \pm 0.0021$ \\
\hline RGI-17.04816 & 24.3 & 99.8 & $-0.401 \pm 0.033$ & $-0.0098 \pm 0.0008$ & 24.3 & 99.1 & $0.202 \pm 0.075$ & $0.0049 \pm 0.0018$ \\
\hline RGI-17.04916 & 24.3 & 90.4 & $-0.261 \pm 0.036$ & $-0.0063 \pm 0.0009$ & 24.3 & 98.1 & $0.147 \pm 0.121$ & $0.0036 \pm 0.0029$ \\
\hline RGI-17.04933 & 21.6 & 100.0 & $-0.606 \pm 0.040$ & $-0.0131 \pm 0.0009$ & 21.6 & 98.6 & $-0.393 \pm 0.123$ & $-0.0085 \pm 0.0026$ \\
\hline RGI-17.04905 & 21.1 & 100.0 & $-0.482 \pm 0.036$ & $-0.0102 \pm 0.0008$ & 21.1 & 100.0 & $0.237 \pm 0.102$ & $0.0050 \pm 0.0022$ \\
\hline RGI-17.04879 & 20.9 & 97.1 & $-0.327 \pm 0.041$ & $-0.0068 \pm 0.0009$ & 20.9 & 88.6 & $0.684 \pm 0.155$ & $0.0143 \pm 0.0032$ \\
\hline RGI-17.04926 & 19.9 & 98.9 & $-0.098 \pm 0.038$ & $-0.0020 \pm 0.0008$ & 19.9 & 97.9 & $0.049 \pm 0.124$ & $0.0010 \pm 0.0025$ \\
\hline Snowy & 20.1 & 97.8 & $-1.027 \pm 0.040$ & $-0.0206 \pm 0.0008$ & 19.8 & 97.0 & $-0.480 \pm 0.081$ & $-0.0095 \pm 0.0016$ \\
\hline RGI-17.04785 & 19.7 & 92.9 & $-0.256 \pm 0.037$ & $-0.0050 \pm 0.0007$ & 19.7 & 93.1 & $0.562 \pm 0.094$ & $0.0111 \pm 0.0018$ \\
\hline Marconi & 19.7 & 82.3 & $-0.840 \pm 0.052$ & $-0.0165 \pm 0.0010$ & 19.4 & 78.3 & $-1.159 \pm 0.178$ & $-0.0225 \pm 0.0035$ \\
\hline RGI-17.04993 & 19.4 & 89.2 & $-1.030 \pm 0.045$ & $-0.0200 \pm 0.0009$ & 18.7 & 81.4 & $-0.667 \pm 0.120$ & $-0.0125 \pm 0.0023$ \\
\hline Tunel Inferior & 18.1 & 97.2 & $-0.737 \pm 0.038$ & $-0.0133 \pm 0.0007$ & 18.1 & 96.9 & $-0.668 \pm 0.093$ & $-0.0121 \pm 0.0017$ \\
\hline RGI-17.15792 & 17.7 & 99.9 & $-0.276 \pm 0.035$ & $-0.0049 \pm 0.0006$ & 17.7 & 99.9 & $-0.020 \pm 0.092$ & $-0.0004 \pm 0.0016$ \\
\hline RGI-17.04884 & 17.0 & 51.3 & $-0.380 \pm 0.066$ & $-0.0065 \pm 0.0011$ & 17.0 & 60.9 & $-0.089 \pm 0.208$ & $-0.0015 \pm 0.0035$ \\
\hline RGI-17.04890 & 16.9 & 98.6 & $-0.265 \pm 0.039$ & $-0.0045 \pm 0.0007$ & 16.9 & 95.8 & $0.188 \pm 0.101$ & $0.0032 \pm 0.0017$ \\
\hline RGI-17.05439 & 16.2 & 80.2 & $-0.078 \pm 0.048$ & $-0.0013 \pm 0.0008$ & 16.2 & 54.6 & $-0.478 \pm 0.157$ & $-0.0077 \pm 0.0025$ \\
\hline RGI-17.04995 & 16.1 & 72.8 & $-0.695 \pm 0.054$ & $-0.0112 \pm 0.0009$ & 16.1 & 95.9 & $-0.702 \pm 0.150$ & $-0.0113 \pm 0.0024$ \\
\hline RGI-17.04901 & 16.1 & 89.4 & $-0.200 \pm 0.043$ & $-0.0032 \pm 0.0007$ & 16.1 & 93.3 & $0.083 \pm 0.128$ & $0.0013 \pm 0.0021$ \\
\hline RGI-17.04862 & 16.1 & 100.0 & $-1.202 \pm 0.040$ & $-0.0193 \pm 0.0006$ & 16.1 & 98.9 & $0.072 \pm 0.081$ & $0.0012 \pm 0.0013$ \\
\hline RGI-17.05092 & 15.7 & 99.1 & $0.196 \pm 0.041$ & $0.0031 \pm 0.0006$ & 15.7 & 97.6 & $-0.413 \pm 0.196$ & $-0.0065 \pm 0.0031$ \\
\hline 04923 & 15.7 & 92.8 & $-0.065 \pm 0.046$ & $-0.0010 \pm 0.0007$ & 15.6 & 95.2 & $0.034 \pm 0.138$ & $0.0005 \pm 0.0022$ \\
\hline RGI-17.04931 & 15.5 & 100.0 & $-0.277 \pm 0.040$ & $-0.0043 \pm 0.0006$ & 15.5 & 98.2 & $0.048 \pm 0.129$ & $0.0007 \pm 0.0020$ \\
\hline RGI-17.06038 & 14.8 & 98.6 & $-0.269 \pm 0.036$ & $-0.0040 \pm 0.0005$ & 14.4 & 94.7 & $-0.842 \pm 0.187$ & $-0.0122 \pm 0.0027$ \\
\hline RGI-17.04991 & 14.0 & 99.8 & $0.101 \pm 0.039$ & $0.0014 \pm 0.0006$ & 14.0 & 98.8 & $-0.035 \pm 0.127$ & $-0.0005 \pm 0.0018$ \\
\hline RGI-17.04878 & 13.9 & 88.5 & $-0.225 \pm 0.046$ & $-0.0031 \pm 0.0006$ & 13.9 & 99.0 & $-0.022 \pm 0.130$ & $-0.0003 \pm 0.0018$ \\
\hline RGI-17.05028 & 13.7 & 87.5 & $-0.327 \pm 0.048$ & $-0.0045 \pm 0.0007$ & 13.7 & 80.0 & $-0.167 \pm 0.213$ & $-0.0023 \pm 0.0029$ \\
\hline RGI-17.04959 & 13.2 & 90.3 & $0.277 \pm 0.051$ & $0.0037 \pm 0.0007$ & 13.0 & 97.5 & $-0.473 \pm 0.122$ & $-0.0062 \pm 0.0016$ \\
\hline RGI-17.05627 & 12.9 & 99.9 & $-0.037 \pm 0.038$ & $-0.0005 \pm 0.0005$ & 12.9 & 99.6 & $-0.030 \pm 0.167$ & $-0.0004 \pm 0.0022$ \\
\hline RGI-17.04885 & 12.8 & 93.6 & $-0.003 \pm 0.050$ & $-0.0000 \pm 0.0006$ & 12.8 & 92.7 & $-0.199 \pm 0.121$ & $-0.0025 \pm 0.0016$ \\
\hline RGI-17.04910 & 12.7 & 99.9 & $-0.369 \pm 0.034$ & $-0.0047 \pm 0.0004$ & 12.7 & 99.9 & $0.392 \pm 0.089$ & $0.0050 \pm 0.0011$ \\
\hline RGI-17.05024 & 12.9 & 99.7 & $-0.295 \pm 0.036$ & $-0.0038 \pm 0.0005$ & 12.6 & 98.9 & $0.010 \pm 0.079$ & $0.0001 \pm 0.0010$ \\
\hline RGI-17.05059 & 12.6 & 99.1 & $0.170 \pm 0.044$ & $0.0021 \pm 0.0006$ & 12.6 & 95.3 & $-0.570 \pm 0.199$ & $-0.0072 \pm 0.0025$ \\
\hline RGI-17.01019 & 12.5 & 63.9 & $0.536 \pm 0.071$ & $0.0067 \pm 0.0009$ & 12.5 & 89.0 & $0.157 \pm 0.145$ & $0.0020 \pm 0.0018$ \\
\hline RGI-17.15748 & 12.5 & 99.9 & $0.188 \pm 0.040$ & $0.0024 \pm 0.0005$ & 12.5 & 99.2 & $-0.316 \pm 0.194$ & $-0.0040 \pm 0.0024$ \\
\hline RGI-17.04946 & 12.2 & 99.9 & $-0.289 \pm 0.042$ & $-0.0035 \pm 0.0005$ & 12.1 & 98.4 & $-0.127 \pm 0.127$ & $-0.0015 \pm 0.0015$ \\
\hline RGI-17.15738 & 11.9 & 90.7 & $-0.251 \pm 0.044$ & $-0.0030 \pm 0.0005$ & 11.9 & 92.2 & $-0.356 \pm 0.203$ & $-0.0042 \pm 0.0024$ \\
\hline RGI-17.05505 & 11.6 & 93.8 & $0.039 \pm 0.046$ & $0.0005 \pm 0.0005$ & 11.6 & 3.4 & $-1.397 \pm 0.305$ & $-0.0163 \pm 0.0036$ \\
\hline RGI-17.04906 & 11.2 & 64.7 & $2.373 \pm 0.058$ & $0.0265 \pm 0.0006$ & 11.2 & 91.5 & $-0.435 \pm 0.162$ & $-0.0049 \pm 0.0018$ \\
\hline RGI-17.05459 & 11.0 & 95.3 & $-0.165 \pm 0.047$ & $-0.0018 \pm 0.0005$ & 11.0 & 0.0 & & \\
\hline RGI-17.15779 & 10.9 & 99.5 & $-0.435 \pm 0.049$ & $-0.0047 \pm 0.0005$ & 10.9 & 96.2 & $0.271 \pm 0.115$ & $0.0029 \pm 0.0013$ \\
\hline RGI-17.15797 & 10.6 & 100.0 & $-1.294 \pm 0.043$ & $-0.0137 \pm 0.0004$ & 10.6 & 100.0 & $-1.379 \pm 0.092$ & $-0.0146 \pm 0.0010$ \\
\hline RGI-17.05022 & 10.3 & 90.6 & $-0.185 \pm 0.039$ & $-0.0019 \pm 0.0004$ & 10.3 & 82.7 & $-0.242 \pm 0.211$ & $-0.0025 \pm 0.0022$ \\
\hline RGI-17.05167 & 9.6 & 97.3 & $0.094 \pm 0.047$ & $0.0009 \pm 0.0004$ & 9.6 & 96.9 & $-0.385 \pm 0.112$ & $-0.0037 \pm 0.0011$ \\
\hline RGI-17.06001 & 9.4 & 99.5 & $0.214 \pm 0.044$ & $0.0020 \pm 0.0004$ & 9.4 & 95.1 & $-0.390 \pm 0.188$ & $-0.0037 \pm 0.0018$ \\
\hline Heim & 9.6 & 83.5 & $-0.375 \pm 0.063$ & $-0.0036 \pm 0.0006$ & 9.3 & 93.9 & $-0.498 \pm 0.157$ & $-0.0047 \pm 0.0015$ \\
\hline RGI-17.05128 & 9.2 & 98.9 & $-0.179 \pm 0.045$ & $-0.0016 \pm 0.0004$ & 9.1 & 99.1 & $-0.359 \pm 0.109$ & $-0.0033 \pm 0.0010$ \\
\hline
\end{tabular}


Table S10. Estimated subaqueous volume changes for SPI glaciers with most significant frontal changes in the period 2000-2011/2012, based on Abdel Jaber (2016). $\Delta t$ : the time span in years; $d_{\mathrm{fr}}$ : glacier retreat at the central part of the front; $\mathrm{VC}_{\text {sub }}$ : subaqueous ice volume loss. * Glaciers where bathymetric data were used, originating from: Naruse and Skvarca (2000); Skvarca et al. (2002); Rivera et al. (2012); Raymond et al. (2005); Stuefer (1999). Following bulk errors were assigned: $20 \%$ for glaciers with bathymetric data, $70 \%$ for HPS 12 , 40 $\%$ for other glaciers.

\begin{tabular}{lccr}
\hline Glacier front & $\Delta t[\mathrm{a}]$ & $d_{\text {fr }}[\mathrm{km}]$ & $\mathrm{VC}_{\text {sub }}\left[\mathrm{km}^{3}\right]$ \\
\hline Upsala W* & 11.2 & 3.45 & $-2.800 \pm 0.560$ \\
Greve & 12.0 & 1.13 & $-0.813 \pm 0.325$ \\
Jorge Montt* & 11.2 & 2.36 & $-0.680 \pm 0.136$ \\
Occidental & 12.0 & 2.2 & $-0.671 \pm 0.268$ \\
HPS 12 & 11.1 & 3 & $-0.655 \pm 0.459$ \\
HPS 9 & 12.0 & 1.13 & $-0.618 \pm 0.247$ \\
HPS 8 & 12.0 & 2.9 & $-0.595 \pm 0.238$ \\
Tyndall* & 11.4 & 1.3 & $-0.590 \pm 0.118$ \\
Amalia & 11.7 & 0.6 & $-0.552 \pm 0.221$ \\
HPS 41 & 11.4 & 1.85 & $-0.539 \pm 0.216$ \\
Balmaceda & 12.0 & 1.48 & $-0.434 \pm 0.174$ \\
Upsala E & 11.2 & $2.4 / 1.3$ & $-0.339 \pm 0.136$ \\
Grey & 11.4 & $0.7 / 0 / 0.7$ & $-0.292 \pm 0.117$ \\
Viedma & 11.2 & 0.82 & $-0.279 \pm 0.112$ \\
Onelli \& Bolados & 12.1 & 2 & $-0.267 \pm 0.107$ \\
O’Higgins & 12.1 & 0.3 & $-0.174 \pm 0.070$ \\
HPS 38 & 11.7 & 1.37 & $-0.168 \pm 0.067$ \\
Lucia & 11.2 & 1 & $-0.132 \pm 0.053$ \\
Dickson & 12.0 & 2.33 & $-0.130 \pm 0.052$ \\
Bernardo W & 12.0 & 0.7 & $-0.079 \pm 0.032$ \\
Ofhidro N & 12.0 & 0.7 & $-0.071 \pm 0.029$ \\
Ofhidro S & 12.0 & 1.38 & $-0.054 \pm 0.022$ \\
Ameghino* & 11.2 & 0.85 & $-0.050 \pm 0.010$ \\
Pio XI N & 12.0 & 0.53 & $0.369 \pm 0.148$ \\
Pio XI S & 12.0 & 1.89 & $2.283 \pm 0.913$ \\
\hline & & & \\
\hline
\end{tabular}




\section{S8 Comparison of volume change rate estimates of NPI and SPI}

Table S11. Overview of volume change rate (VCR) results on NPI, SPI or both icefields. * Mass change rate (MCR) based on gravimetry, converted using $\rho_{\text {ice }}=900 \mathrm{~kg} \mathrm{~m}^{-3}$ when VCR not given. ${ }^{\star}$ Geodetic MCR converted to VCR using $\rho_{\text {ice }}=900 \pm 125 \mathrm{~kg} \mathrm{~m}^{-3}$ (Foresta, 2018 ).

$\dagger$ "SPOT-SRTM” method; * “ASTER_trend” method (Dussaillant et al., 2018).

\begin{tabular}{lccl}
\hline Reference & Region & Period & VCR $\left[\mathrm{km}^{3} \mathrm{a}^{-1}\right]$ \\
\hline Rignot et al. (2003) & NPI & $1968 / 75-2000$ & $-3.2 \pm 0.4$ \\
Willis et al. (2012a) & NPI & $2000-2011$ & $-4.1 \pm 0.1$ \\
Willis et al. (2012b) & NPI & $2000-2011$ & $-4.9 \pm 0.3$ \\
Abdel Jaber (2016) & NPI & $2000-2014$ & $-4.4 \pm 0.1$ \\
Dussaillant et al. (2018) & NPI & $2000-2012$ & $-4.6 \pm 0.4^{\dagger}$ \\
Dussaillant et al. (2018) & NPI & $2000-2012$ & $-4.7 \pm 0.3^{\star}$ \\
Foresta et al. (2018) & NPI & $2011-2017$ & $-7.5 \pm 0.8^{\star}$ \\
This study & NPI & $2000-2012$ & $-4.3 \pm 0.2$ \\
This study & NPI & $2012-2016$ & $-5.6 \pm 0.7$ \\
\hline Rignot et al. (2003) & SPI & $1968 / 75-2000$ & $-13.5 \pm 0.8$ \\
Rignot et al. (2003) & SPI & $1995-2000$ & $-38.7 \pm 4.4$ \\
Willis et al. (2012b) & SPI & $2000-2012$ & $-21.2 \pm 0.5$ \\
Abdel Jaber (2016) & SPI & $2000-2011 / 12$ & $-14.6 \pm 0.4$ \\
Malz et al. (2018) & SPI & $2000-2015$ & $-13.2 \pm 3.6$ \\
Foresta et al. (2018) & SPI & $2011-2017$ & $-16.1 \pm 1.4^{\star}$ \\
This study & SPI & $2000-2012$ & $-14.9 \pm 0.5$ \\
This study & SPI & $2012-2016$ & $-11.9 \pm 2.0$ \\
\hline Chen et al. (2007) & NPI+SPI & $2001-2006$ & $-27.9 \pm 11.0^{*}$ \\
Ivins et al. (2011) & NPI+SPI & $2003-2009$ & $-28.9 \pm 6.7^{*}$ \\
Jacob et al. (2012) & Patagonia & $2003-2010$ & $-25.6 \pm 10.0^{*}$ \\
Willis et al. (2012b) & NPI+SPI & $2000-2011 / 12$ & $-26.1 \pm 0.6$ \\
Abdel Jaber (2016) & NPI+SPI & $2000-2011 / 12 / 14$ & $-19.0 \pm 0.4$ \\
Foresta et al. (2018) & NPI+SPI & $2011-2017$ & $-23.7 \pm 1.6^{\star}$ \\
This study & NPI+SPI & $2000-2012$ & $-19.1 \pm 0.6$ \\
This study & NPI+SPI & $2012-2016$ & $-17.5 \pm 2.1$ \\
\hline
\end{tabular}

Table S12. Comparison of our volume change rate (VCR) results with those of Foresta et al. (2018) for the glaciers and sub-regions defined in their study. We re-converted their reported mass change rates to VCR using $\rho_{\text {ice }}=900 \pm 125 \mathrm{~kg} \mathrm{~m}^{-3}$ (Foresta, 2018). The group of glaciers "SPI-G1" includes basins north of Pio XI and Viedma excluding Jorge Montt, "SPI-G2" includes all glaciers west and south of Upsala excluding Grey and Tyndall. Cov. is the percentage of area coverage of the surface elevation change maps.

\begin{tabular}{lrrrrrrr}
\hline & \multicolumn{2}{c}{ Foresta et al. (2018) $(2011-2017)$} & & \multicolumn{2}{c}{ This study (2012-2016) } \\
\cline { 2 - 3 } \cline { 7 - 8 } Region & Area $\left[\mathrm{km}^{2}\right]$ & Cov. [\%] & VCR $\left[\mathrm{km}^{3} \mathrm{a}^{-1}\right]$ & & Area $\left[\mathrm{km}^{2}\right]$ & Cov. [\%] & VCR $\left[\mathrm{km}^{3} \mathrm{a}^{-1}\right]$ \\
\hline NPI & 4046.4 & 45.7 & $-7.54 \pm 0.75$ & & 3914.2 & 89.8 & $-5.60 \pm 0.74$ \\
Jorge Montt & 474.4 & 68.0 & $-2.44 \pm 0.25$ & & 471.2 & 98.6 & $-2.33 \pm 0.10$ \\
Upsala & 863.1 & 61.3 & $-2.98 \pm 0.16$ & & 823.5 & 99.3 & $-2.50 \pm 0.11$ \\
Viedma & 992.3 & 72.7 & $-2.52 \pm 0.19$ & & 971.3 & 98.9 & $-2.23 \pm 0.13$ \\
SPI-G1 & 3570.1 & 47.4 & $-5.63 \pm 0.40$ & & 3667.8 & 97.1 & $-5.42 \pm 0.66$ \\
SPI-G2 & 4829.5 & 39.1 & $-1.84 \pm 1.26$ & & 4943.8 & 95.6 & $-0.04 \pm 0.68$ \\
Tyndall & 332.0 & 49.9 & $-0.67 \pm 0.13$ & & 302.2 & 98.4 & $-0.48 \pm 0.03$ \\
Grey & 333.3 & 54.0 & $-0.77 \pm 0.23$ & & 304.4 & 96.4 & $-0.07 \pm 0.04$ \\
Pio XI & 1242.6 & 65.0 & $0.74 \pm 0.31$ & & 1246.7 & 98.5 & $1.26 \pm 0.25$ \\
SPI total & 12637.2 & 49.9 & $-16.11 \pm 1.43$ & & 12846.8 & 97.0 & $-11.86 \pm 1.99$ \\
\hline
\end{tabular}




\section{References}

Abdel Jaber, W.: Derivation of mass balance and surface velocity of glaciers by means of high resolution synthetic aperture radar: application to the Patagonian Icefields and Antarctica, Dissertation, Technische Universität München, http://elib.dlr.de/109075/, 2016.

Bravo, C., Quincey, D., Ross, A., Rivera, A., Brock, B., Miles, E., and Silva, A.: Air Temperature Characteristics, Distribution, and Impact on Modeled Ablation for the South Patagonia Icefield, Journal of Geophysical Research: Atmospheres, 124, 907-925, 2019.

Chen, J. L., Wilson, C. R., Tapley, B. D., Blankenship, D. D., and Ivins, E. R.: Patagonia icefield melting observed by gravity recovery and climate experiment (GRACE), Geophysical Research Letters, 34, 2007.

Dussaillant, I., Berthier, E., and Brun, F.: Geodetic Mass Balance of the Northern Patagonian Icefield from 2000 to 2012 using two independent methods, Frontiers in Earth Science, 6, 8, 2018.

Foresta, L., Gourmelen, N., Weissgerber, F., Nienow, P., Williams, J., Shepherd, A., Drinkwater, M., and Plummer, S.: Heterogeneous and rapid ice loss over the Patagonian Ice Fields revealed by CryoSat-2 swath radar altimetry, Remote Sensing of Environment, 211, 441-455, 2018.

Foresta, L. U.: Applications of CryoSat-2 swath radar altimetry over Icelandic ice caps and Patagonian ice fields, Ph.D. thesis, The University of Edinburgh, 2018.

Ivins, E. R., Watkins, M. M., Yuan, D.-N., Dietrich, R., Casassa, G., and Rülke, A.: On-land ice loss and glacial isostatic adjustment at the Drake Passage: 2003-2009, Journal of Geophysical Research: Solid Earth, 116, https://doi.org/10.1029/2010JB007607, 2011.

Jacob, T., Wahr, J., Pfeffer, W. T., and Swenson, S.: Recent contributions of glaciers and ice caps to sea level rise, Nature, 482, 514-518, 2012.

Malz, P., Meier, W., Casassa, G., Jaña, R., Skvarca, P., and Braun, M. H.: Elevation and mass changes of the Southern Patagonia Icefield derived from TanDEM-X and SRTM Data, Remote Sensing, 10, 188, 2018.

Naruse, R. and Skvarca, P.: Dynamic features of thinning and retreating Glaciar Upsala, a lacustrine calving glacier in southern Patagonia, Arctic, Antarctic, and Alpine Research, pp. 485-491, 2000.

Raymond, C., Neumann, T. A., Rignot, E., Echelmeyer, K., Rivera, A., and Casassa, G.: Retreat of Glaciar Tyndall, Patagonia, over the last half-century, Journal of Glaciology, 51, 239-247, 2005.

Rignot, E., Rivera, A., and Casassa, G.: Contribution of the Patagonia Icefields of South America to sea level rise, Science, 302, 434-437, 2003.

Rivera, A.: Mass balance investigations at Glaciar Chico, Southern Patagonia Icefield, Chile, Ph.D. thesis, University of Bristol, 2004.

Rivera, A., Benham, T., Casassa, G., Bamber, J., and Dowdeswell, J. A.: Ice elevation and areal changes of glaciers from the Northern Patagonia Icefield, Chile, Global and Planetary Change, 59, 126-137, 2007.

Rivera, A., Koppes, M., Bravo, C., and Aravena, J. C.: Little ice age advance and retreat of Glaciar Jorge Montt, Chilean Patagonia, Climate of the Past, 8, 403-414, 2012.

Rizzoli, P., Martone, M., Rott, H., and Moreira, A.: Characterization of snow facies on the Greenland ice sheet observed by TanDEM-X interferometric SAR data, Remote Sensing, 9, 315, 2017.

Rott, H., Sturm, K., and Miller, H.: Active and passive microwave signatures of Antarctic firn by means of field measurements and satellite data, Annals of Glaciology, 17, 337-343, 1993.

Schaefer, M., Machguth, H., Falvey, M., and Casassa, G.: Modeling past and future surface mass balance of the Northern Patagonia Icefield, Journal of Geophysical Research: Earth Surface, 118, 571-588, 2013.

Seal, D. and Rogez, F.: SRTM As-Flown Mission Timeline, Tech. rep., JPL NASA, http://www2.jpl.nasa.gov/srtm/SRTM_TIM_AF.pdf, 2000.

Skvarca, P., De Angelis, H., Naruse, R., Warren, C., and Aniya, M.: Calving rates in fresh water: new data from southern Patagonia, Annals of Glaciology, 34, 379-384, 2002.

Stuefer, M.: Investigations on mass balance and dynamics of Moreno Glacier based on field measurements and satellite imagery, Ph.D. thesis, University of Innsbruck, Austria, 1999.

Stuefer, M., Rott, H., and Skvarca, P.: Glaciar Perito Moreno, Patagonia: climate sensitivities and glacier characteristics preceding the 2003/04 and 2005/06 damming events, Journal of Glaciology, 53, 3-16, 2007.

Willis, M. J., Melkonian, A. K., Pritchard, M. E., and Ramage, J. M.: Ice loss rates at the Northern Patagonian Icefield derived using a decade of satellite remote sensing, Remote Sensing of Environment, 117, 184-198, 2012a.

Willis, M. J., Melkonian, A. K., Pritchard, M. E., and Rivera, A.: Ice loss from the Southern Patagonian Ice Field, South America, between 2000 and 2012, Geophysical Research Letters, 39, 2012b. 